\title{
Causas de alteración y métodos de conservación aplicables a los monumentos hechos con piedra
}

JOSE M.a CABRERA GARRIDo, Dr. en Ciencias Quimicas Jefe del Laboratorio del Instituto de Conservación y Restauración de obras de Arte

\begin{abstract}
Con motivo del Curso de Estudios Mayores de la Construcción "CEMCO-79" dedicado a la Patología de la Construcción, que se ha celebrado en el Instituto Eduardo Torroja de la Construcción y del Cemento, $y$ al que han asistido diversos ingenieros $y$ arquitectos iberoamericanos, el Dr. José M. ${ }^{a}$ Cabrera Garrido pronunció tres conferencias que versaron sobre: "Los defectos y protección en las obras de piedra"; "Alteraciones de las piedras en los monumentos", y "Procedimientos para la conservación de monumentos".
\end{abstract}

Con estas tres conferencias el Dr. Cabrera ha pretendido dar una panorámica general de los problemas y soluciones actuales en la conservación de las esculturas líticas en los exteriores de nuestros Monumentos.

\section{MECANISMOS DE ALTERACION}

\section{Introducción}

La fidelidad a lo auténtico en Conservación de Bienes Culturales es más o menos posible según los medios que se ponen en acción.

Desde el punto de vista técnico siempre se han utilizado los sistemas más ingeniosos y eficaces, de tal suerte que van parejos con los recursos tecnológicos más avanzados de cada época. Pues bien, los métodos que se disponen actualmente nos permiten un acercamiento, cada vez en mayor número de casos y con mejor éxito, a la fórmula ideal: conservar el objeto de forma duradera y con todo lo que en él nos llega de auténtico, de vivo y de verdadero. 
Hace ya bastantes años, y no precisamente por invención nuestra, que tenemos muy claras las que son notas exigibles a los métodos de conservación y, seguramente, serán muy similares en su valor genérico a las que resultan preceptivas en otros ámbitos de la actividad humana. Para conservar en un monumento importante su auténtica dimensión cultural, se ha de mantener dentro de un equilibrio de factores cuya resultante no es la renovación ni el cambio, sino la permanencia y la estabilidad. Acciones exteriores y reacciones interiores han de constituir un sistema de fuerzas en equilibrio. Cuando fuera de ese sistema, por motivos ocasionales o continuos, aparece una fuerza extraña o existe en la materia incapacidad de reacción, se altera el equilibrio alcanzado y sobreviene la ruina.

En general, la Conservación de los Bienes Culturales se programa sobre dos líneas de operación principales: restaurar los daños existentes y mejorar las características del clima en su entorno y, en este esfuerzo, hemos de mantener la tensión buscando en cada caso la opción más justa dentro de los criterios de la experiencia acumulada, trabajando con los recursos pacientemente contrastados de que disponemos, y aportando cuantas ideas y métodos - nacidos de la Ciencia y de la Tecnología modernas- colaboren en nuestro empeño hasta el final de las posibilidades objetivas.

En este coniexto, la piedra esculpida que adorna el exterior de nuestros monumentos más señeros, constituye aún uno de los retos importantes al conservador, por estar a la intemperie. Desde el punto de vista metodológico y de forma similar a la pintura rupestre en cuevas y abrigos, su conservación la entendemos cada vez más como un fenómeno dependiente del tipo de equilibrio que en cada caso se establezca con su ecosistema.

Las causas que alteran estos equilibrios son de muy distinta naturaleza y origen y, siendo su modo de actuar muy diferente, se comprenderá lo complejo que resulta su estudio y lo dificultoso de su análisis. El conservador tiene que investigar, reunir y confrontar todos los elementos de apreciación posibles en torno a los signos y los síntomas de los daños, para así poder razonar y enjuiciar sus causas.

Tal es el fundamento del diagnóstico, base imprescindible del método de Conservación, más seguro éste cuanto más claro y cierto sea aquél. El fracaso en muchas intervenciones ha tenido por origen un error de diagnóstico, debido generalmente a un mal planteamiento del problema ante un proceso equivocado o incompleto en la determinación de las causas, ya sea por deficiencia de medios para la aportación de datos o por dificultad en relacionar éstos con rigurosa independencia.

Dentro de los límites que nos marca el objetivo de estas tres conferencias, he querido permanecer en la línea de estudiar aplicaciones a casos concretos, sustentando las teorías y las opiniones en experiencias recientes para que así puedan ser calificadas, en contraste con la realidad, porque se está de acuerdo en afirmar que, en el estado actual de nuestros conocimientos, cabe esperar una importante ayuda de las operaciones controladas y adaptadas a problemas específicos, ya que permiten asegurarse una interacción de datos que contribuyen al mejor conocimiento de los problemas generales. La abundante utilización de la imagen acentuará la diferencia entre la palabra hablada y la escrita, pero este divorcio lo considero insalvable.

\section{Alteración por sales solubles en agua}

Son probablemente la causa más frecuente de deterioración de los materiales pétreos y, sea cual fuere su procedencia, se ponen en movimiento por el agua y se acumulan en 
las superficies de evaporación, en donde cristalizan. Los aportes de agua líquida y los cambios en la humedad relativa del aire hacen que estas sales cristalicen, eflorezcan o se disuelvan, fenómeno que al repetirse acaba por comprometer la solidez de los materiales más resistentes.

En el caso de las piedras de la Catedral de León, la composición química de las sales es principalmente a base de sulfatos de magnesio y algo de calcio, habiendo también una proporción menor de cloruros, nitratos y bicarbonatos, sodio y potasio.

La procedencia de estas sales puede ser diversa. Algo contienen ya los materiales originales, según se ve en el análisis realizado, y también pueden haber sido aportadas por los materiales de restauración (cal, cemento, arena, agua, etc.); también el aire contaminado es una importante fuente al reaccionar los gases ácidos de la combustión del petróleo y carbón en automóviles y calefacciones con los compuestos carbonatados de la piedra, con preferencia en las zonas más enriquecidas con minerales ricos en hierro que actúan como catalizador en la formación de ácido sulfúrico; también, en muchas de las zonas bajas de los muros, estas sales pueden proceder del suelo y ser arrastradas por el agua que asciende en los muros por acción de la succión capilar, pudiendo estas sales ser originarias del propio suelo, haber sido aportadas por salmueras para eliminar el hielo del suelo en los inviernos, abonos minerales o como residuos de productos empleados en tratamientos anteriores que se hayan aplicado, como es el caso de los silicatos aplicados a uno de los tímpanos del pórtico occidental, que por hidrólisis del éster libera una parte de componentes, quizás alcalinos, y otras veces por el empleo de fungicidas, antihielo, etc. En otros casos, especialmente en climas húmedos y calientes, las sales son de ácidos orgánicos como húmicos, etc. procedentes de suelos en buen estado pedológico o como consecuencia de una ocupación humana por los restos orgánicos que se acumulan alrededor del monumento.

En los muros, el agua migra a través de los capilares arrastrando las sales que luego se difunden, se hidrolizan o precipitan y que, ante un gradiente térmico, sus componentes iónicos migran hacia las partes más calientes, mientras que el agua lo hace hacia las más frías, produciendo así acumulación de compuestos solidos, ya sea en la superficie cuando el agua aflora regularmente durante los procesos de evaporación, o debajo de ella cuando el frente de líquido retrocede, según indica Knetsch (38).

Los sulfatos son depositados en los poros, desde sus soluciones sobresaturadas, como cristales de alto contenido en agua, de hidratos como $\left(\mathrm{SO}_{4} \mathrm{Mg} .6 \mathrm{H}_{2} \mathrm{O}, \mathrm{SO}_{4} \mathrm{Ca} .2 \mathrm{H}_{2} \mathrm{O}, \mathrm{SO}_{4} \mathrm{Na}_{2}\right.$. $.10 \mathrm{H}_{2} \mathrm{O}$, etc.) y cuando la evaporación prosigue la sal efloresce secando fuera, forman. do una masa de agregados microcristalinos que por su fina estructura promueven el flujo de más disoluciones, desde el interior de los poros hacia la superficie, rellenando el volumen de poros detrás de la superficie de evaporación. Cuando se produce un aumento de la humedad relativa del aire, que alcance el valor de la presión de vapor específica de cada cristal antes señalado, se hidratarán estos cristales provocando un aumento de volumen y, por tanto, una presión sobre las paredes de los poros equivalente a la presión de hidratación en el caso de que su crecimiento se vea impedido. La formación de eflorescencias y de sales hidratadas depende de su presión de vapor y de la temperatura. De acuendo con esto, una sal hidratada pierde su agua de cristalización si la presión de vapor del hidrato, a una temperatura determinada, es más alta que la presión parcial del vapor de agua en el aire a esa misma temperatura; cuando sucede al contrario la sal se hidrata. Por ejemplo, en el caso de una disolución de sulfato sódico, a temperaturas por debajo de $32,4^{\circ} \mathrm{C}$, la sal precipita como un compuesto con diez moléculas de agua de cristalización, 
pero para temperaturas mayores se transforma en sal anhidra; al aumentar la h.r. por debajo de esta temperatura puede reconvertirla en el hidrato parcial o totalmente, según el grado de diferencia entre la h.r. y la presión de vapor de la sal a cada temperatura dada. Por esto, la cuantía del daño resultante de este proceso repetitivo de contracción y expansión sobre las paredes de los poros depende de la presión que puede ejercer la sal y que se señala en el cuadro adjunto.

Actualmente, se considera de gran importancia el estudio de la resistencia de los materiales frente a los fenómenos de cristalización de sales, habiéndose seleccionado como sal patrón para un intento de normalizar ensayos en el Grupo de trabajo de la RILEM 25 PEM, el sulfato de sodio. Todas las ponencias aportadas en este sentido, a la última reunión UNESCO-RILEM de junio de 1978, coinciden en afirmar que aún no se dispone de una rutina de operación válida capaz de permitir la normalización del ensayo que sería de desear. Aunque los avances en este sentido se vienen produciendo con bastante lentitud siguen siendo válidas las estimaciones realizadas por Butterwoth (6) para quien, disolu-

Presiones de cristalización de sales (84)

\begin{tabular}{|c|c|c|c|c|c|c|}
\hline \multirow{3}{*}{ Fórmula } & \multicolumn{6}{|c|}{ Presión de cristalización (atm) } \\
\hline & \multicolumn{2}{|c|}{$\mathbf{R c}=\mathbf{2}$} & \multicolumn{2}{|c|}{$\mathbf{R c}=10$} & \multicolumn{2}{|c|}{$\mathbf{R c}=\mathbf{5 0}$} \\
\hline & $\mathbf{0}^{\circ} \mathbf{C}$ & $50^{\circ} \mathbf{C}$ & $\mathbf{O} \mathbf{C}$ & $50^{\circ} \mathrm{C}$ & $\mathbf{O}^{\circ} \mathbf{C}$ & $50^{\circ} \mathbf{C}$ \\
\hline $\mathrm{SO}_{4} \mathrm{Ca}$ & 335 & 398 & 1.120 & 1.325 & 1.900 & 2.262 \\
\hline $\mathrm{SO}_{4} \mathrm{Ca} . \mathrm{H}_{2} \mathrm{O}$ & 282 & 334 & 938 & 1.110 & 1.595 & 1.900 \\
\hline $\mathrm{SO}_{4} \mathrm{Mg} \cdot \mathrm{H}_{2} \mathrm{O}$ & 272 & 324 & 910 & 1.079 & 1.543 & 1.840 \\
\hline $\mathrm{SO} \mathrm{Mg} 6 \mathrm{H}_{2} \mathrm{O}$ & 118 & 141 & 395 & 469 & 671 & 800 \\
\hline $\mathrm{SO}_{4} \mathrm{Na}_{2}$ & 292 & 345 & -970 & 1.150 & 1.650 & 1.965 \\
\hline $\mathrm{SO}_{4} \mathrm{Na}_{2} .10 \mathrm{H}_{2} \mathrm{O}$ & 72 & 83 & 234 & 277 & 397 & 473 \\
\hline $\mathrm{ClNa}$ & 554 & 654 & 1.845 & 2.190 & 3.135 & 3.737 \\
\hline $\mathrm{Cl}_{2} \mathrm{Mg} .6 \mathrm{H}_{2} \mathrm{O}$ & 119 & 142 & 397 & 470 & 675 & 803 \\
\hline
\end{tabular}

$R c=$ Relación entre la concentración actual de soluto durante la cristalización y la concentración de saturación.

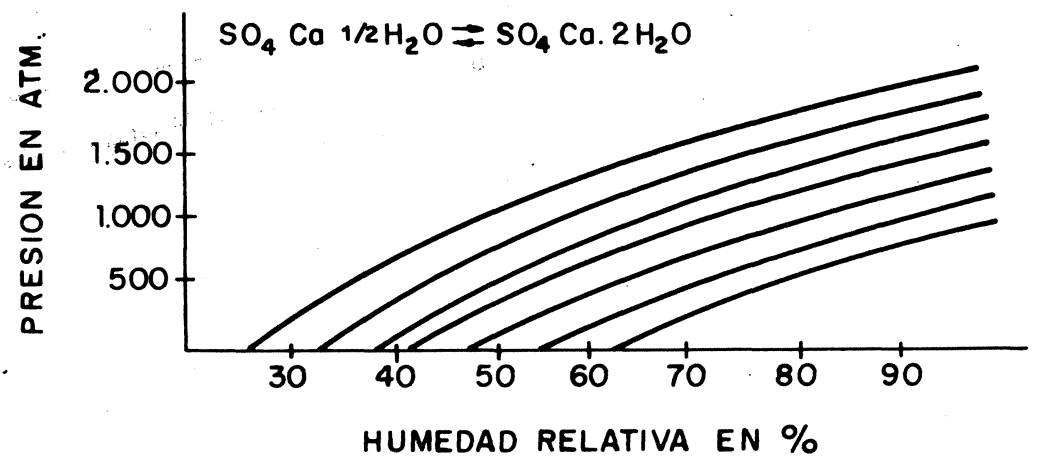

Presiones de hidratación para varias temperaturas $y$ h.r. (84). 
ciones conteniendo más de $0,1 \%$ de sulfatos pueden considerarse como peligrosas para los materiales porosos, ya que por tener estos poros una sección transversal irregular (no circular), la evaporación de soluciones no permite un retiro gradual del menisco hacia el interior, permitiendo una difusión de la concentración hacia adentro, sino que en los puntos donde terminan los ejes mayores de esa curvatura irregular, o al menos elíptica, el menisco se desplaza menos y la menor pérdida por evaporación se compensa por un suministro lateral, resultando una sobresaturación local que deposita las sales en los puntos en que el poro es más fino, ejerciéndose una mayor presión destructora.

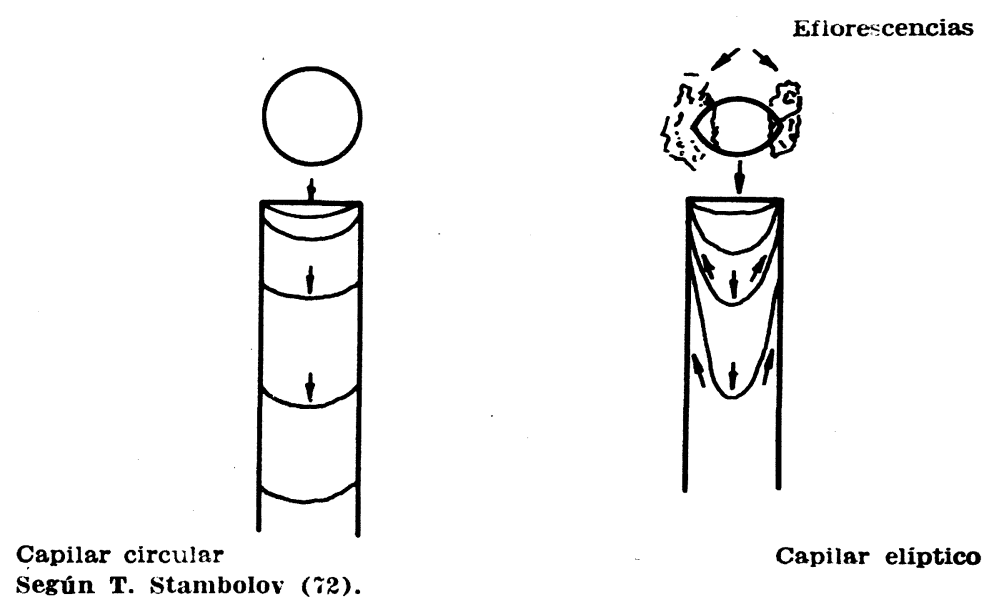

Completamente distinta es la acción de los cloruros, nitratos y sales de ácidos orgánicos. Los cloruros son muy higroscópicos y durante la condensación del agua son los primeros en disolverse $\mathrm{y}$, en disolución, se comportan muy activamente por su extraordinaria movilidad y capacidad de corrosión penetrando y rompiendo numerosas estructuras cristalinas, aumentando la falta de estequiometría en los cristales y peptizando grandes aglomerados de moléculas que pueden así ser transportadas por el agua. Este grupo se caracteriza por arenizar los materiales que los contienen.

En general, el movimiento de las disoluciones salinas en el interior de los poros de las rocas, tiende a empobrecerlas en materiales cementantes, rellenándose los poros de la superficie a expensas del debilitamiento interno y creándose costras en la superficie bajo la cual se desarrolla una estructura de corrosión subdividida en capas. Cuando las sales responsables de la costra son poco solubles, el material adquiere una patina estable como las formadas a base de fosfatos, hidróxidos de hierro, etc.

Un aspecto absolutamente específico de las posibles reacciones químicas, entre los diferentes iones presentes en las disoluciones, merece un comentario detallado:

La reacción entre el sulfato de magnesio y el cloruro de sodio según:

$$
\mathrm{SO}_{4} \mathrm{Mg}+2 \mathrm{ClNa} \Longleftrightarrow \mathrm{SO}_{4} \mathrm{Na}_{2}+\mathrm{Cl}_{2} \mathrm{Mg}
$$

conduce a la formación de un par salino recíproco con punto de transformación a $32^{\circ} \mathrm{C}$ aproximadamente, correspondiendo la menor solubilidad al $\mathrm{SO}_{4} \mathrm{Na}_{2} \cdot 10 \mathrm{H}_{2} \mathrm{O}$ que cristalizará el primero, por lo que es a él a quien se deben atribuir parte de los daños y no sólo al sulfato de magnesio. 
Por otra parte, la reacción entre el ClNa y el $\mathrm{Ca}(\mathrm{OH})_{2}$ del mortero de cal utilizado para ligar los sillares y que, como en tantas otras construcciones antiguas, se encuentra en parte sin carbonatar aún en el interior de los muros, puede escribirse como:

$$
2 \mathrm{ClNa}+\mathrm{Ca}(\mathrm{OH})_{2} \Longleftrightarrow \mathrm{Cl}_{2} \mathrm{Ca}+2 \mathrm{NaOH}
$$

pudiendo transformarse esta porción de sosa en carbonato de sodio por acción del $\mathrm{CO}_{2}$ atmosférico, que a su vez induciría la precipitación de los carbonatos alcalinotérreos, cerrándose así una especie de ciclo salino.

Otros mecanismos, tales como la posible reacción entre el ClNa y el bicarbonato de calcio o magnesio para producir bicarbonato de sodio de menor solubilidad, o también la reacción entre el ClNa y los carbonatos de calcio, de magnesio o de calcio y magnesio para dar los carbonatos de sodio y los cloruros alcalinotérreos, exigen una discusión más detenida: pues no resultan totalmente claros.

En muchas ocasiones se ha considerado como cierta la descomposición del carbonato de calcio por el cloruro de sodio, según la idea inaugurada por Berthollet (1) al estudiar la formación del Natrón de los lagos salados de Egipto y así vemos como, por ejemplo Moore (48), dice en su libro de texto que: "él sabía que la reacción

$$
\mathrm{CO}_{3} \mathrm{Na}_{2}+\mathrm{Cl}_{2} \mathrm{Ca} \rightarrow \mathrm{CO}_{3} \mathrm{Ca}+2 \mathrm{ClNa}
$$

como se realiza en los laboratorios, era total al precipitar todo el carbonato de calcio, pero tuvo que admitir que cuando existía un gran exceso de ClNa la reacción podía ser inversa transformando la calcita en carbonato de sodio". También Iñiguez (30) al revisar la bibliografía de "Chimie der Erde" entre 1926 y 1938, hace las siguientes observaciones:

a) Sobre los trabajos de Storz concernientes a la acción química de disoluciones salinas sobre la calcita y la formación subsiguiente de carbonato de sodio, anota que todo eso permitiría explicar ciertos tipos de alteraciones, pero que no puede ser el factor más importante puesto que la presencia de cloruros no es frecuente fuera de las zonas costeras.

b) Comenta la reacción

$$
\mathrm{CO}_{3} \mathrm{Ca} \text { (sol) }+\mathrm{SO}_{4} \mathrm{Na}_{2} \text { (liq) } \Longleftrightarrow \mathrm{SO}_{4} \mathrm{Ca} \text { (sol) }+\mathrm{CO}_{3} \mathrm{Na}_{2} \text { (liq) }
$$

notando que sólo puede tener lugar en pequeña proporción dada la relación de equilibrio $\mathrm{CO}_{3}=/ \mathrm{SO}_{4}=1,56 \times 10^{-4}$.

Al revisar lo escrito por Berthollet (1), en 1803, vemos que acepta la descomposición del carbonato de calcio por el cloruro de sodio basándose en la tendencia a eflorescer del carbonato de sodio, e indica que la reacción está favorecida por la existencia de un soporte poroso como es la roca que favorezca la separación de las sales frente a un cierto grado de humedad; señala que este fenómeno se puede apreciar también sobre la superficie de ciertas bóvedas y de algunos muros. Recoge también las observaciones hechas por Guyton (Mem. de Schéele, part. II) según las cuales si se incorporan disoluciones de $\mathrm{SO}_{4} \mathrm{~K}_{2} \mathrm{O}$ 


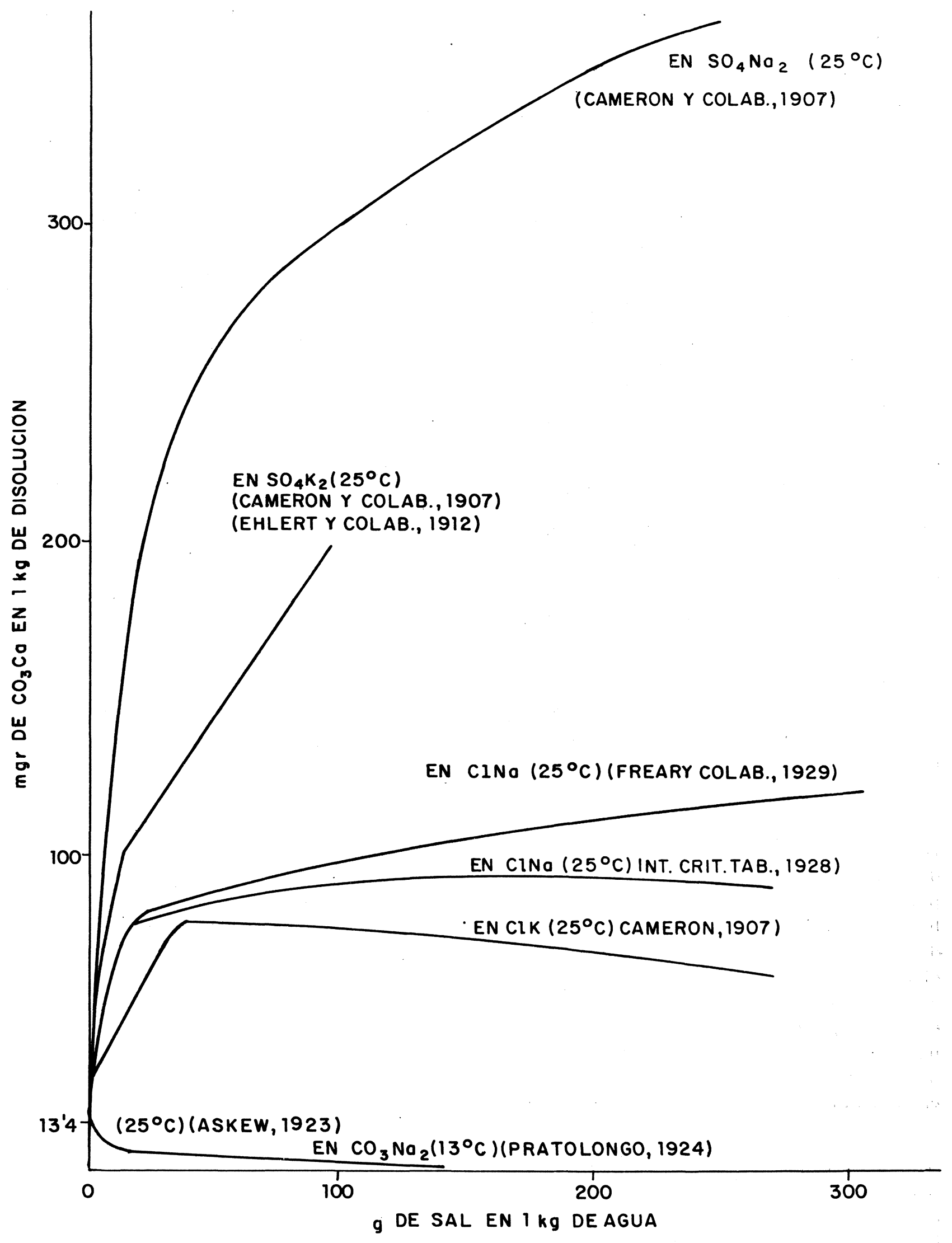

Solubilidad del $\mathrm{CO}_{3} \mathrm{Ca}$ en disoluciones salinas 
de $\mathrm{ClK}$ al agua de cal lechosa por estar cargada de $\mathrm{CO}_{2}$, hacen desaparecer inmediatamente el precipitado y que, de la misma forma, no se produce precipitado cuando se vierte una mezcla de agua de cal y de disolución de estas sales neutras sobre agua cargada de $\mathrm{CO}_{2}$.

A la vista de estas observaciones, hemos procedido a recopilar los valores conocidos de la solubilidad del carbonato de calcio en disoluciones salinas, reflejando los datos en forma gráfica para señalar mejor las diferencias notables en los resultados recopilados por Linke (41), Seidel (68), Stephen (74) y los de "The International Critical Tables of Numerical Data" que representan una recopilación masiva, pero sin interpretar los datos en términos de constantes de equilibrio.

En nuestra opinión, la acción química que las sales solubles pueden ejercer sobre las rocas calizas y dolomitas de la Catedral de León debe considerarse secundario frente a la acción mecánica que esas mismas sales desempeñan en los procesos de alteración.

\section{Daños por heladas}

En zonas frías, como León, los materiales húmedos se alteran principalmente por la acción del hielo que, desde antiguo, se ha venido considerando peligroso a la vista del aumento de volumen de aproximadamente $9 \%$ que experimenta el agua al congelarse, pues la presión que la congelación brusca a $-5^{\circ} \mathrm{C}$ ejerce es del orden de $500 \mathrm{~kg} / \mathrm{cm}^{2} \mathrm{y}$, en estas condiciones, el hielo no tiene tiempo ni dentro de los poros vacíos ni hacia el exterior.

Este modelo de interpretación del mecanismo de rotura por el hielo quedó en evidencia al considerarse (27) que estas condiciones de congelación repentina no se dan siempre en el interior de los materiales pétreos, que además son malos conductores térmicos y, especialmente, por el hecho de que el deterioro también se observa cuando un líquido como el nitrobenceno que hiela sin aumento de volumen, se encuentra dentro de los poros.

El mecanismo de congelación del agua en el interior de los poros se explica actualmente de la siguiente manera: Cuando un poro está lleno de agua y se enfría por debajo del punto de congelación, se empiezan a formar depósitos laminares de hielo desde el menisco hacia adentro. Las moléculas quedan inmovilizadas en la partícula de hielo y, por debajo de ella, el movimiento molecular disminuye creándose una diferencia de presión entre el frente de congelación y el resto del agua en el capilar por lo que, para restablecer el equilibrio, el agua migra hacia la partícula de hielo y debido a que su tensión superficial es mayor que el peso de la incipiente partícula de hielo hace que ésta se levante y migre en el interior del capilar, aumentando al mismo tiempo de volumen por la película de agua que la rodea; de su formación resulta un drenaje de los capilares próximos y el crecimiento del grano de hielo, en donde el poro es más fino.

La interpretación del fenómeno ha evolucionado. En 1908 Hirschwald (26) definió un "coeficiente de saturación" trabajando sobre la teoría del aumento de volumen del $10 \%$, relacionando el volumen de poros fácilmente accesible con el volumen total de poros abiertos, y con arreglo a esto se dictaron los ensayos normalizados DIN 52103 y 52105.

En los últimos años se han realizado investigaciones más intensas sobre esto recogidas por la RILEM, y se reconoce que todos los materiales pueden ser destruidos por el hielo cuan- 
do la cantidad de agua incluida en sus poros alcance el "contenido crítico" (contenido de agua constante a distintos tiempos en la curva de secado), con lo cual se provoca una expansión tal que se alcanza en el material el "alargamiento límite de ruptura".

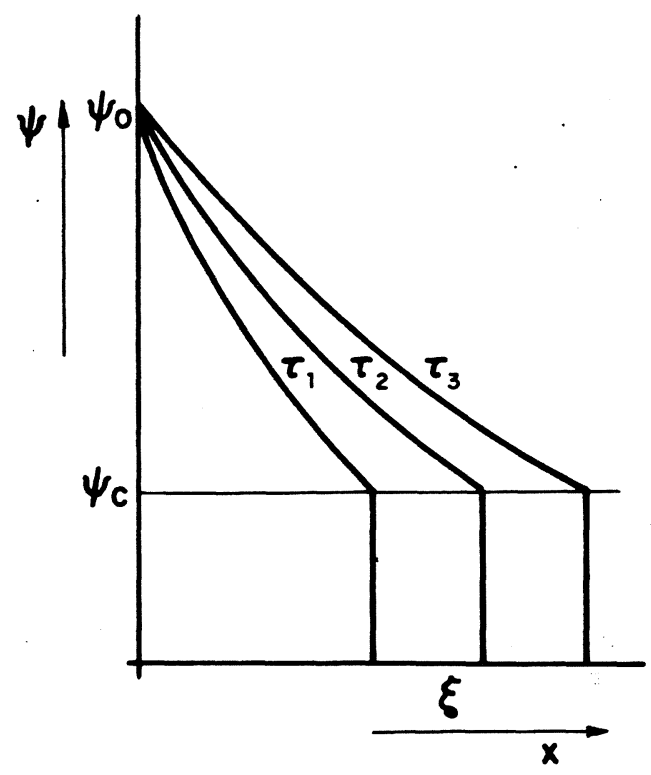

Proceso de absorción de agua: Distribución del agua ( $\psi$ ) en un material poroso a diferentes tiempos $(\tau)$.

$\xi$ : Situación del frente de agua.

$\psi_{\text {c }}:$ Contenido crítico.

$\psi_{0}:$ Contenido máximo.

Según H. Vos (80).

De todas formas, esta hipótesis general es también un poco simplista, puesto que en la realidad de los fenómenos no son nunca puros, ya que existen heterogeneidades locales en el contenido de agua o gradientes térmicos que provocan tensiones en puntos concretos, y también sucede que aun sin alcanzarse el alargamiento límite, se produzca un fenómeno de fatiga debido a la repetición de las contracciones y expansiones de la formación del hielo.

Cuando las piedras han perdido su "agua de cantera" y han sido colocadas correctamente en el monumento, en el sitio que a cada una le corresponda por sus características intrínsecas, en ese momento ninguna piedra es alterable o no alterable por el hielo, puesto que esto depende de que sus poros contengan un nivel iguali o superior al contenido crítico de agua. Luego, estos materiales serán capaces de alcanzar o no este valor crítico de humedad, en función de su localización en las distintas partes del monumento a lluvia, filtraciones, ascensión capilar, etc., y a la estructura de sus poros.

Mamillan (44) ha publicado sus investigaciones experimentales del daño por el hielo y ha demostrado que para responder de una forma razonable al problema de resistencia al hielo de las piedras es necesario tener en cuenta estos dos factores: "ambiente de exposición" y "estructura del material". Gérard (20) ha normalizado en Bélgica, recientemente, tres ensayos para la heladicidad. 


\section{Alteración por cambios de temperatura}

Se dice también que lo que provoca la formación de placas en las piedras antiguas de la Catedral, pudiera ser por la relajación que se acusa en materiales sometidos a fuerte insolación, pero esto no sería aplicable con igual intensidad a los paramentos expuestos al norte, en donde también se observan daños similares.

Los cambios de temperatura pueden actuar sobre la solidez de la roca de varias formas: Por una parte, el coeficiente de conductividad térmica para estas calizas varía entre 0,8 y $2,5 \mathrm{kcal} / \mathrm{m} / \mathrm{h} /{ }^{\circ} \mathrm{C}$, por lo que tan bajo valor, unido a las considerables variaciones de temperatura entre el día y la noche, en las zonas expuestas a mayor insolación, podrían hacer que nacieran tensiones entre el núcleo de la piedra y su superficie, y originar daños, lo que en nuestro caso es difícil de tipificar por existir piedras alteradas similares en todas
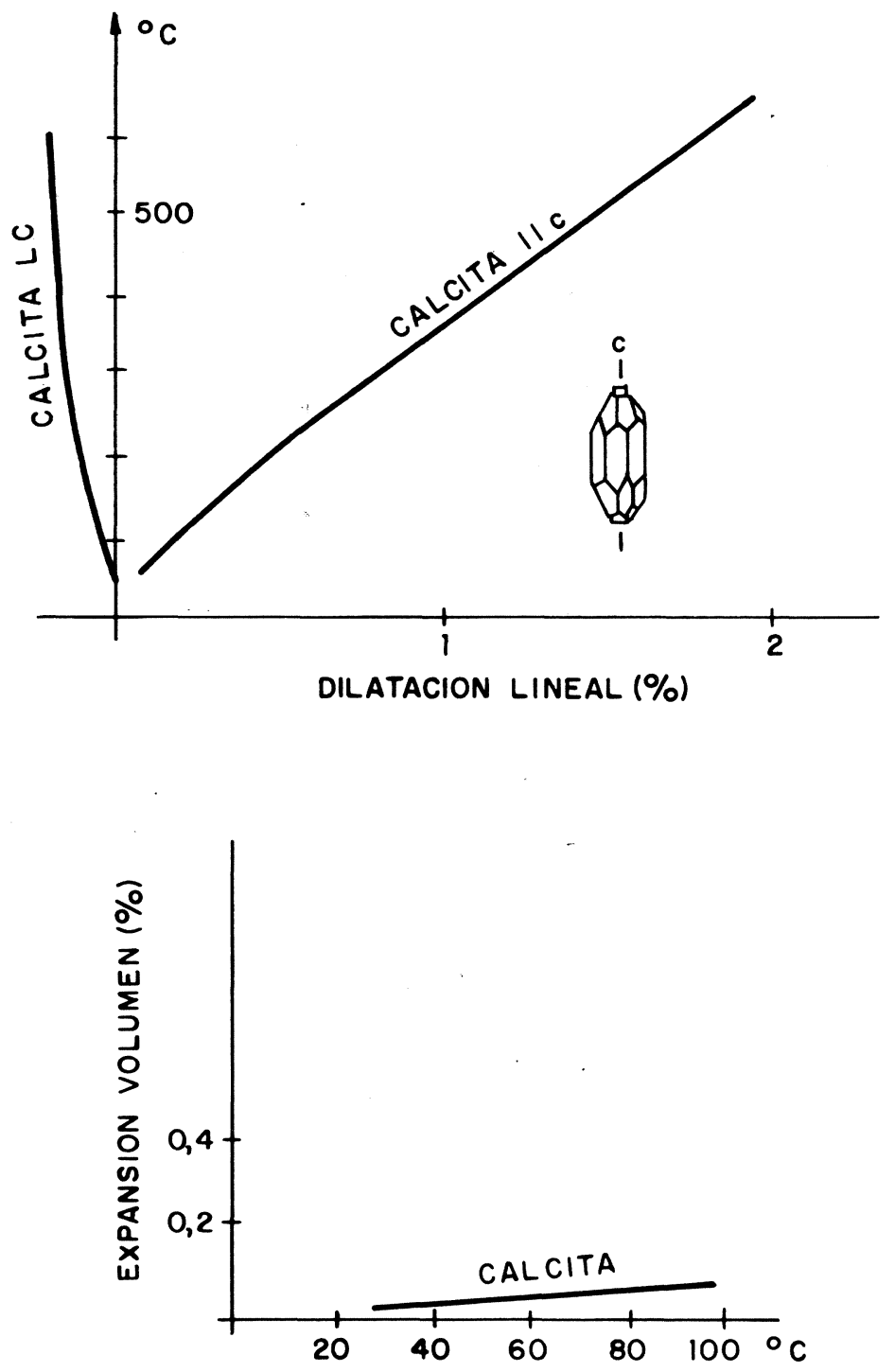

las orientaciones y piedras bien conservadas en iguales exposiciones. También, el coeficiente de dilatación térmica de los minerales son diferentes entre ellos, y muchos cristales tienen expansiones diferentes según los distintos ejes, por lo que los cambios de temperatura causan tensiones internas capaces de producir, según Kieslinger (36), la desagregación de una caliza debido a que la calcita tiene una dilatación mayor según su eje princi- 
pal. Para Sneyers (70), este fenómeno de anisotropía térmica es la causa de que aun en regiones templadas se produzcan deformaciones importantes por deslizamiento de los planos cristalinos entre ellos, hasta alcanzar un nuevo estado de equilibrio que se manifiesta por una deformación permanente. Además, según Warnes (82), cuando la roca se enfría no se contrae la misma cantidad, y esta deformación o modificación, que es permanente, contribuye también al daño. Otro punto a discutir es que las variaciones de temperatura del agua en el interior de los poros de la roca puede provocar una cierta erosión, dado que el coeficiente de dilatación del agua es muy superior al de las rocas y, según Sneyers (70), las variaciones de humedad reguladas por las variaciones de temperatura pueden desunir los cristales al transformarse en gotitas una película intergranular de agua, puesto que se modifica la presión capilar que es inversamente proporcional al radio de curvatura.

En un caso similar a éste de calizas sulfatadas, Schaffer (66) atribuye el levantamiento de costras a las variaciones térmicas, puesto que la superficie transformada en yeso se calienta más y tiene un coeficiente de dilatación térmica cinco veces mayor que la calcita subyacente; para él, las contracciones y dilataciones repetidas acaban por separar la costra sulfatada del material de base.

Pero la importancia capital de la temperatura es indirecta, puesto que regula la humedad en los poros de la roca, la solubilidad de los gases y de las sales disueltas, la velocidad de las reacciones químicas y, especialmente, la hidrólisis que se duplica aproximadamente para una elevación de temperatura de $10^{\circ} \mathrm{C}$.

NOTA:

Aunque en la Catedral de León se produjo un incendio hace pocos años, que destruyó las techumbres en toda la nave mayor, el calor no afectó a los materiales pétreos adyacentes.

\section{Erosión por los contaminantes atmosféricos}

Una de las principales causas de daño en la piedra de la Catedral de León es sin duda la "sulfatación".

Si bien no existe un estudio exhaustivo de la contaminación atmosférica a nivel de los distintos puntos de la fábrica, similar al realizado por Bertolaccini y otros (2), en los monumentos de Venecia, o por Luckat (43), en la Catedral de Colonia, etc., la atmósfera de León está tan contaminada por humos de vehículos, calefacciones, etc., como la de cualquier otra ciudad de España, utilizándose combustibles fósiles de alto contenido en azufre, lo que justifica la presencia de abundantes síntomas de alteración sobre las calizas de la Catedral a nivel de formación de costras, sales, etc.

El $\mathrm{SO}_{2}$ y el $\mathrm{SO}_{3}$ son los componentes de la contaminación atmosférica que participan más activamente en estas formas de deterioración. Durante la combustión, se producen normalmente en la proporción 10:1 respectivamente pero, en la atmósfera, se transforma el primero en el segundo por la acción de varios mecanismos de oxidación en los que intervienen la luz, humedad, y catalizadores tales como el óxido férrico, etc. Al asociarse estos gases con gotitas de agua o de polvo fino, se forman aerosoles en los que, para el $\mathrm{SO}_{3}$ pueden ser de ácido sulfúrico a las temperaturas normales, puesto que la presión par- 
cial del gas por ser menor de $10^{-4}$ tor, es capaz de reducir el punto de rocío del sistema ácido sulfúrico/agua. Esto que llamamos humos, son en realidad emisiones compuestas por gases, partículas sólidas (polvo, cenizas, hollín, etc.) y líquidas (condensaciones de productos sin quemar como el gasoil o productos de la pirogenación como los alquitranes). E1 tamaño de estas partículas puede variar desde submicrométricas hasta las que tienen una fracción de milímetro, siendo las más grandes, por regla general, las más pesadas, por lo que se depositan pronto; pero las más ligeras pueden difundirse mucho.

Los mecanismos que hacen que estos gases entren en contacto con la superficie de las piedras, impregnándolas gradualmente, son principalmente debidos a la lluvia (que lava la atmósfera), la gravedad (que deposita las partículas de polvo que llevan absorbidos los gases y la humedad), la acción de los aerosoles líquidos y sólidos por atracción eléctrica (las piedras suelen estar cargadas negativamente), y también influye la conductividad térmica de la piedra pues, cuanto mayor sea ésta, más rápidamente se enfría el material y mayor es la condensación de aerosoles.

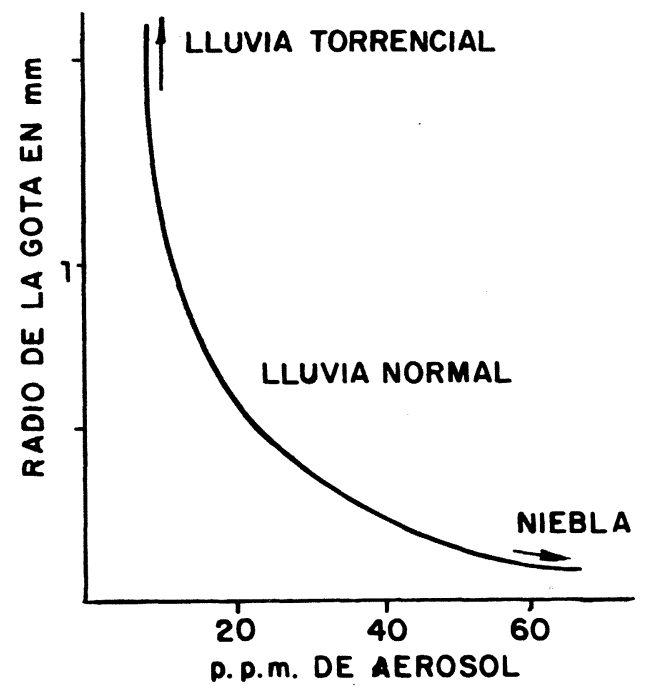

Relación entre el radio de las gotas de lluvia en $\mathrm{mm}$, y la cantidad de aerosol arrastrado en p.p.m.

Las gotas pequeñas de caida lenta, son más activas que las grandes.

Según Winkler (84).

Los efectos del aire contaminado sobre los materiales de construcción han sido estudiados detenidamente y lo siguen siendo en la actualidad. Los procesos de corrosión se conducen en la interfase ácido sulfúrico/piedra y conducen a la transformación de los materiales calcáreos (calizas, dolomitas, mármoles, morteros y enlucidos de cal, pinturas al fresco, etc.) en yeso y sulfato de magnesio, así como a la formación de sales de Candlot a partir de los minerales de alúmina, como también a la aparición de las peligrosísimas disoluciones de sulfatos alcalinos y de magnesio. Serra (69) ha vuelto a estudiar recientemente la reactividad del $\mathrm{SO}_{2}$ sobre el carbonato de calcio en fase heterogénea viendo que la cantidad de gas absorbida y transformada depende dei grado de humedad y de las características de superficie del material. Degranges y otros (16) han visto que una gran parte del $\mathrm{SO}_{2}$ fijado en la piedra se encuentra ligado bajo una forma de alta energía, aunque no especifican sobre la naturaleza de esta ligazón. 
La acción del ácido sulfúrico sobre el carbonato de calcio y magnesio empieza por la descomposición del carbonato, y de la disolución cristalizan los sulfatos correspondientes Las costras de sulfatación, estudiadas por Romanovski (62), tienen un espesor de 0,1 a $1 \mathrm{~mm}$ y están compuestas por $20-30 \%$ de sulfatos, $2-20 \%$ de carbonatos, $0,2-0,5 \%$ de cloruros y 0,2-0,3\% de compuestos de hierro. A $1 \mathrm{~cm}$ de profundidad, la roca tiene la misma composición que en la cantera, pero entre la costra y la roca inalterada hay varias capas con diferentes contenidos en sulfatos y diferentes estados de desagregación, conformando esa compleja estructura de corrosión a que antes hemos aludido en el apartado sobre alteración por sales solubles en agua.

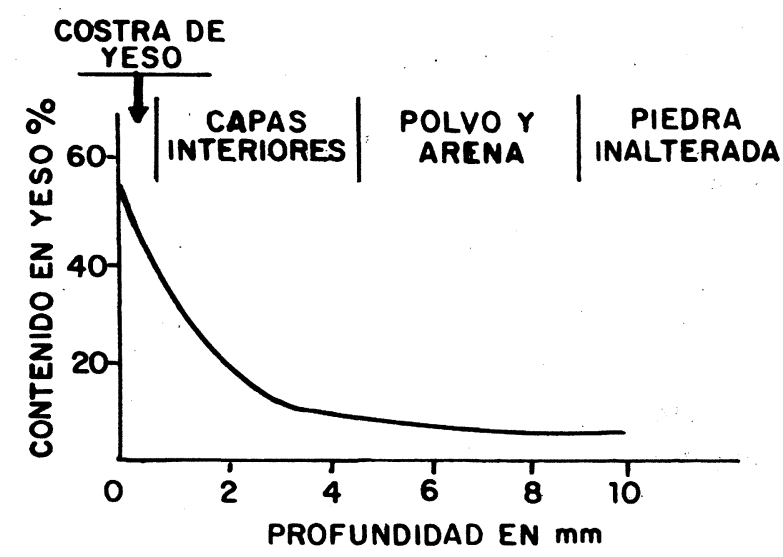

Para piedras como la de Burgos, casi exentas de carbonato de magnesio, el modelo de formación de costras se asemeja profundamente al definido por M. Mamillan (45), al estudiar las características del estado de superficie de piedras calizas sulfatadas:

1. La dureza aumenta respecto a la parte interna, incluso hasta un $60 \%$.

2. La densidad también aumenta respecto al material subyacente, incluso hasta en un $25 \%$.

3. ${ }^{a}$ La permeabilidad al agua en la superficie se reduce respecto a la roca sana hasta en un $50 \%$, pero no llega a ser totalmente impermeable.

4. La capacidad de evaporación disminuye paralelamente hasta en un $50 \%$.

5. La composición química de la capa superficial indica que se ha producido una disminución en el contenido de carbonato de calcio y un aumento en el de sulfato de calcio.

En todos los monumentos, y también en la Catedral de León, las costras de sulfatación se forman principalmente en las superficies protegidas de la lluvia, en la parte baja de las cornisas o dentro de los huecos de los modelados que no se lavan fácilmente. Cuando como en nuestro caso, tanto para la caliza de Burgos como para la dolomita de León, las piedras no resisten a los humos, las costras se desprenden de la piedra, se forman ampollas, se desagrega y se exfolia la superficie, dejando al descubierto la parte interior que es pulverulenta y fácilmente erosionable por la lluvia y el viento.

En nuestro caso, junto con los sulfatos, también encontramos otras sales que contribuyen a hacerlos más peligrosos aún. Teniendo en cuenta que la solubilidad del yeso en agua es 
relativamente grande (202 $\mathrm{mg}$ por $100 \mathrm{~g}$ de agua) y que la presencia de estas otras sales aumenta aún más esta solubilidad, así como la presencia de los peligrosísimos sulfatos de magnesio y también algo del de sodio, muy solubles y capaces de formar cristales muy voluminosos, se comprende que las repetidas disoluciones y cristalizaciones de estas sales, provocadas simplemente por los cambios acentuados en h.r. del aire, además de por lluvias y otros aportes de humedad, acaben por comprometer la solidez de las rocas que impregnan.

Aunque el $\mathrm{SO}_{2}$ es la causa principal de la alteración de las piedras calizas y dolomías por acción de los contaminantes atmosféricos, debemos señalar que unas se alteran más que otras y especialmente las calizas se comportan mucho mejor que las dolomitas. Aun para las calizas, algunas forman una capa exterior estable y se comportan de forma satisfactoria, lo que se explica considerando que las causas de alteración son generalmente muy complejas e intervienen conjuntamente diversos factores, y esto hace que la verdadera resistencia de las piedras a la atmósfera contaminada sólo se conozca aún de forma empírica por medio de la observación de su comportamiento en los monumentos. En esto, la Catedral de León puede considerarse como una verdadera planta experimental en cuanto a la existencia de diferentes materiales de distintas fechas de utilización, en diferentes grados de alteración, etc. e incluso materiales de la misma cantera colocados en la misma época que se comportan de diferente forma, quizás por proceder de distintos bancos, etc. Todo esto da un valor experimental extraordinario al conjunto de los materiales de la Catedral de León y nos hacen ver en este monumento una dimensión poco frecuente de testimonio técnico para las más modernas líneas de investigación pura y aplicada, que será necesario perfilar con exactitud a través del estudio de la "historia material" de la Catedral que proponíamos antes, y que tendremos que explotar inexcusablemente mediante programas coherentes de estudio que sirvan para este y para otros monumentos.

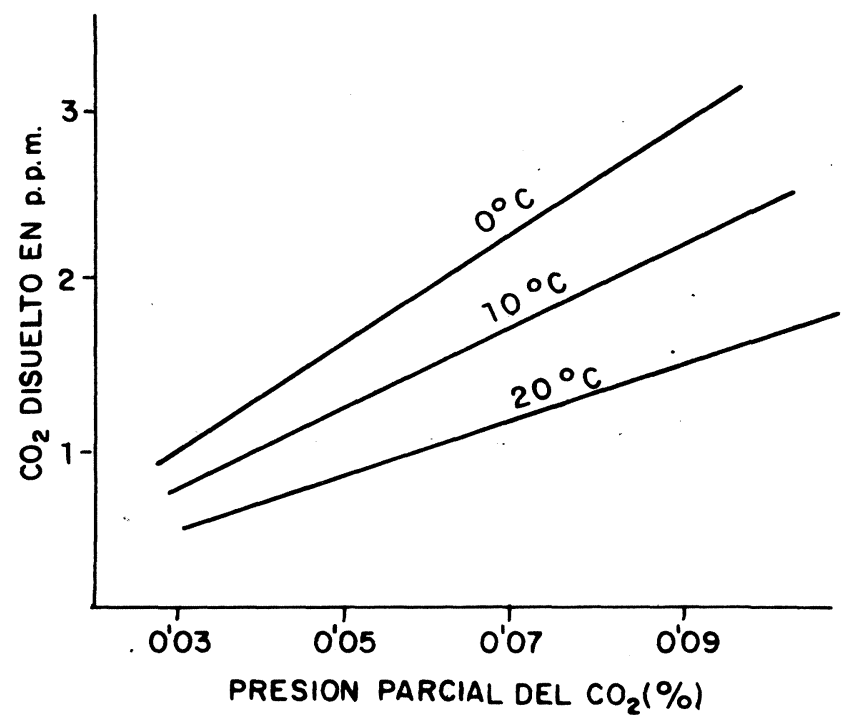

Los nitratos que encontramos en los análisis pueden proceder también de los que se añaden a la atmósfera durante los procesos de combustión, aunque también es frecuente encontrar un alto contenido (desde $2,9 \mathrm{~g} / \mathrm{m}^{3}$ a 8,4 y en adelante) después de intensas tormentas eléctricas. Se acepta que estos gases de ácido nítrico contribuyen también a la corrosión de las piedras, pero también sucede que sufren una alteración fotoquímica al mezclarse con los hidrocarburos presentes en el aire, produciendo oxidantes fuertes, aunque el nivel oxidante se mida generalmente sólo por el contenido en ozono que también se forma en las tormentas y que contribuye intensamente a la transformación rápida del $\mathrm{SO}_{2}$ en $\mathrm{SO}_{3}$.

18 
Un constituyente muy importante y no tóxico de la atmósfera es el $\mathrm{CO}_{2}$, que en zonas rurales alcanza un promedio de $0,034 \%$ y en zonas contaminadas puede representar más del $0,27 \%$ y que procede en su mayor parte de los procesos de combustión de materia carbonosa. La cantidad de anhídrido carbónico disuelto en el agua influye en la solubilidad de los carbonatos y acelera la descomposición de los constituyentes silicatados. Todos los minerales carbonatados aumentan su solubilidad al aumentar la presión parcial del $\mathrm{CO}_{2}$ en el agua. En los minerales silicatados, la disolución no es un proceso tan simple y puede verse con detalle en el trabajo de Keller y colaboradores (35) entre otros.

Winkler (85) viene estudiando reiteradamente la alteración de las rocas de los monumentos por acción de los contaminantes atmosféricos, $\mathrm{y}$ ha tratado de definir una escala de la velocidad del daño estimándolo visualmente y con fotografías; señala que la velocidad de erosión por contaminantes es lenta al principio, cuando la roca está aún fresca y nueva, pero que progresa rápidamente y toma la forma de una función exponencial a medida que el daño progresa y se acumulan los productos salinos, etc. que son los motores del daño.

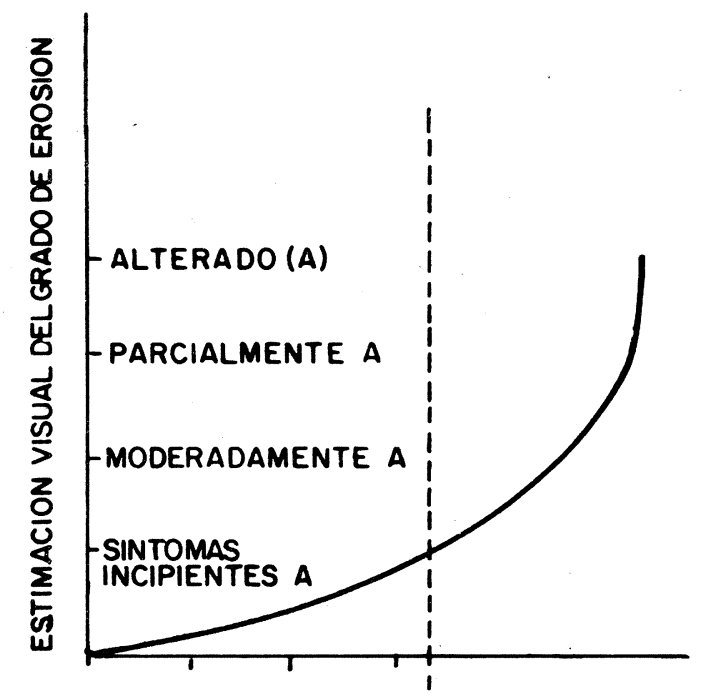

\section{Alteración por agentes biológicos}

Las plantas superiores que crecen en algunos puntos de la Catedral, enraizándose en las juntas entre sillares o entre losas de la terraza del pórtico occidental, o en los conductos de evacuación del agua sobre los contrafuertes, etc. suelen ser causa de alteraciones más que por ellas mismas por indicar que allí es alto el contenido de humedad y por actuar ejerciendo una mayor retención del agua. Se les considera más como el resultado de una atención poco asidua que como factor de alteración propiamente dicho.

Especialmente sobre la caliza de Burgos se puede observar la presencia de líquenes de tipo calcífilo que también indican que el sustrato de roca posee, frecuentemente, un contenido alto de humedad. Los líquenes, asociación simbiótica de un alga y un hongo, tienen un crecimiento lento. Lallement y Deruelle (39) han vuelto a replantear recientemente la cuestión de si los líquenes sobre los monumentos son más un factor de daño o de protección, cuestión que se discute desde que se comenzaron a estudiar por Linneo en el siglo XVIII; esta polémica se replanteó a mediados de nuestro siglo y así vemos que 
mientras Cooper y Rudolh (15), Hale (24), Beschel (3) y Tezuka (77) opinan que la alteración de la superficie de las rocas es tan insignificante que solamente una gran ignorancia puede llevar a la conclusión de que son importantes transformadores de la roca en suelo; Clements y Shelford (13), Schatz y Martín (67), y Williams y Rudolph (83) consideran que los líquenes se encuentran entre los principales agentes de alteración bioquímica implicados en la transformación de la roca desnuda en un suelo. Los primeros investigadores evaluaron el papel de los líquenes, en la alteración de las rocas, basándose en observaciones de campo; los primeros trabajos se refirieron fundamentalmente a los efectos mecánicos, pero ya desde el siglo XIX se remarca la facilidad de producir $\mathrm{CO}_{2}$ y ácido oxálico y, más recientemente, sobre su capacidad de producir agentes complejantes de cationes, todo lo cual actúa degradando el sustrato rocoso.

Los líquenes están presentes en la Catedral de León, y en otros muchos monumentos, y su presencia, normal, se cuida en unos casos por "razones de estética" mientras que en otros casos se les persigue por razones similares.

La capacidad de los líquenes para atacar la superficie de las rocas comporta dos aspectos principales:

a) Su carácter esponjoso hace que retengan la humedad en la piedra subyacente pudiendo contribuir a un daño posterior, pues mantienen un contenido de agua en la roca casi continuamente por encima del valor crítico $\mathrm{y}$, dado que uno de los principales mecanismos de alteración, se debe al número de ciclos mojado-secado de la piedra, tales áreas están preservadas frente a la acción de las sales porque el número de ciclos es pequeño, pero peligran respecto a posible acción de heladas $\mathrm{y}$, sobre todo, las partes adyacentes y las correspondientes en el interior presentan un grado de alteración más elevado.

b) Por secreción de ácidos y cambio iónico. El pequeño catión $\mathrm{H}^{+}$, producido por los rizomas de los líquenes y por las raíces de las plantas ataca el sustrato con el que intercambia los iones nutrientes.

En nuestro caso, al levantar las colonias liquénicas existentes sobre la piedra de Burgos, se puede observar con absoluta claridad que la piedra está mejor conservada que en las zonas desprovistas de ellos y por esto, al margen de cualquier otra consideración, podemos considerarlos más como protectores de la roca que como causa de alteración en el sentido edafogénico con que los investigadores se pronuncian inflexiblemente.

En algunas zonas expuestas al norte y sometidas a humedades casi constantes, se aprecia la existencia de algas verdes y azules, a lo que no podemos tampoco atribuir, por ellas mismas, una importancia decisiva en el proceso de alteración de las rocas que aquí nos interesa, aunque suponen manchas y demuestran la existencia de humedades.

Tampoco a los hongos se les puede atribuir una función clara en los procesos de alteración de las rocas. Según Henderson y Duff (25) los hongos Aspergillum Niger, Spicaria sp. y Penicillum sp., producen cantidades considerables de ácidos cítrico y oxálico, pero a partir de disoluciones de glucosa al $5 \%$, y se han comprobado daños en pinturas murales hechas al temple por atacar el aglutinante orgánico, pero a todo esto no podemos atribuirle un papel de consideración en nuestro caso actual. 
A los microorganismos, no obstante, sí parece que hemos de atribuirles una influencia en algunos procesos de alteración de las piedras pero, desde un punto de vista cuantitativo, esta influencia también ha sido puesta en duda. Las investigaciones conducidas primero por el Profesor Pochon (56), más tarde por Pochon y Jaton (57) y otros colaboradores, y actualmente también por Jaton en piedras de monumentos, tratan de aclarar este aspecto del problema que es el que se considera de mayor interés dentro del ámbito de los mecanismos biológicos de alteración de las rocas.

En calizas y areniscas utilizadas en la constr xccón de monumentos, Pochon (58 y 60 ) y Pochon y Coppier (59) observaron la presencia de tiobacilos; las lesiones en que los encontraron se caracterizaban por un alto contenido en sulfatos y, en ellas, se aislaron por primera vez estos tiobacilos oxidantes de los sulfuros. El mecanismo que encontraron comprendía la reducción de sulfatos a sulfuros en el suelo próximo a la cimentación (Desulfovibrio Desulfuricans) y éstos eran arrastrados dentro de los muros por el agua de succión capilar.

La alteración en unas calizas con costras que no contenían sulfatos, pero sí nitratos, fue observada por Kauffmann (33) y Kauffmann y Toussaint (34), pudiendo aislar bacterias nitrificantes que oxidan el nitrógeno, presente en el aire y en el agua de lluvia, a nitratos, y éstos convierten el carbonato de calcio en nitrato de calcio soluble. Ensayando sobre piedras sanas las bacterias nitrificantes aisladas en las lesiones, se reprodujo el fenómeno de corrosión.

Para las bacterias heterotrofas se escribe generalmente que no son muy importantes en estos fenómenos de alteración, excepto cuando existe abundante materia orgánica, ya que las bacterias pueden excretar sustancias corrosivas.

En todo este complejo y difícil mundo de los agentes microbiológicos podemos retener los siguientes conceptos:

Según Pochon (60), los grupos funcionales que intervienen de forma más notoria en los procesos de alteración de las piedras son relativamente pocos: esencialmente se trata de los autótrofos "nitrificantes" del ciclo del nitrógeno que generan nitratos y los del ciclo del azufre 1) oxidantes que generan sulfatos y 2) mineralizadores del azufre orgánico, todos ellos generadores de $\mathrm{SH}_{2}$. Finalmente se puede también considerar que en la corrosión de areniscas quizás intervengan bacterias que atacan a los silicatos, pero su acción es aún dudosa.

Se acepta normalmente que para decidir sobre la importancia de los mecanismos de alteración biológica observados sobre una piedra alterada, debemos conocer lo siguiente:

1) La presencia de organismos en número suficiente como para explicar el fenómeno observado.

2) Aislar e identificar esos organismos.

3) Reproducir el fenómeno observado cualitativa y cuantitativamente, inoculando el organismo en un material sano. 
Un ejemplo que demuestra la importancia de este punto 3) quedó bien patente según Hueck (28) en los estudios sobre la corrosión microbiológica del acero pues, aunque se aislaron bacterias capaces de producir la corrosión, el daño que producen es cuantitativa. mente poco importante; esto indica que la corrosión microbiológica del acero existe, pero que no es el único ni el más importante de los factores. Las dificultades propias de esta clase de experiencias hace que no se realicen siempre, y esto ayuda a la confusión en algunos casos.

La identificación de los organismos es un punto de importancia relativamente menor, pese a todo lo que normalmente se dice, porque no es siempre cierto que el organismo haya sido propiamente identificado ya que la taxonomía cambia continuamente al mismo tiempo.

Al primero de esos tres puntos antes indicados es al que se atribuye mayor importancia. Los microorganismos, por estar presentes en casi todas las zonas del exterior, existen sobre casi todas las piedras, pero deben ser más numerosos en las alteraciones en las que intervengan como factores primarios o secundarios y, por consiguiente, se han de poder contar empleando técnicas de análisis cuantitativo.

Según Pochon (57) el análisis, por lo menos al principio, no debe ser para la determinación de la especie en el sentido taxonómico del término, sino más bien para la de la función bioquímica y fisiológica que le caracteriza o mejor aún, para la de la función mayor del conjunto presente sea cual fuere la posición sistemática de las especies que la componen; él mismo recomienda unas técnicas de estudio para determinar cuantitativamente bacterias, actinomicetos, hongos y algas.

En la actualidad, el estudio de estos factores microbiológicos se realiza dentro de programas más amplios en los que se consideran los análisis de sales, rocas, humedades, y otros ingredientes capaces de influir en los procesos activando las lesiones. En el estado actual de nuestros conocimientos y aún en el caso más frecuente de las bacterias del ciclo del azufre y, en especial, los tiobacilos que existen sobre lesiones de sulfatación, es difícil discriminar la proporción de sulfatos debidos a aportes físicos y químicos (contaminación, sales del mar o del suelo, etc.), y los originados exclusivamente por el metabolismo biológico.

En nuestro caso, si bien pueden existir bacterias sobre las piedras de la Catedral que están sulfatadas, las determinaciones globales cuantitativas nos indican que el número de colonias es reducido y que, por tanto, su contribución en la producción de sulfatos debe considerarse poco significativa.

\section{HUMEDAD EN LOS MUROS}

\section{Introducción}

La humedad tiene gran importancia en todos los procesos de erosión de la piedra de la Catedral de León y de todos los demás monumentos, aceptándose que es un elemento común en el origen de casi todas las formas de alteración actuando como matriz de casi todos los procesos químicos, físicos o biológicos que afectan a las piedras: las roturas por el 
hielo no son posibles sin la humedad, los ciclos de las sales solubles tampoco se darían en su ausencia, la reacción de los contaminantes atmosféricos con las piedras secas serían menos nocivos, etc.

Por regla general, los términos "muro húmedo" y "ambiente húmedo" se emplean continuamente sin escala de referencia y se aplican indistintamente para todos los muros y para todos los ambientes más o menos cargados de agua, de tal forma que la apreciación cuantitativa del fenómeno sigue dependiendo normalmente de la opinión personal del observador sin ser traducida a cifras.

Para cuantificar la humedad, como indica Massari (46), son imprescindibles las determinaciones del porcentaje de agua que contienen los materiales, y no sólo para diagnosticar los problemas, sino también para evaluar la eficacia de las soluciones que convenga emplear. Para comprender los efectos y razonar las medidas terapéuticas más adecuadas a cada caso, hemos de basarnos en los modelos de razonamiento establecidos por los especialistas.

En lo que concierne a las medidas de la h.r. del aire y a su influencia en los procesos de condensación, etc. no nos detendremos aquí más que para hacer incapié en el concepto de "microclima" para el espacio atmosférico que rodea un monumento o un muro, así como al más reciente de "nanoclima" introducido por Romanovski (63), que nos hace considerar las condiciones atmosféricas relativas a una superficie reducida que tenga características particulares: en efecto, si bien es importante medir las características del aire en la región, es más importante conocer el clima en contacto con las parcelas de los materiales que presentan problemas.

En la Catedral de León se presenta con toda evidencia el problema de absorción de agua, tanto en todas las partes bajas de los muros por efecto de la succión capilar de la roca, como en los paramentos exteriores expuestos a vientos dominantes por efectos de la lluvia.

Nos circunscribiremos a exponer los principios que rigen los fenómenos de absorción de agua y, a continuación, avanzaremos un juicio crítico esquemático sobre los métodos de eliminar humedades normalmente en uso por los especialistas. Finalmente estudiaremos someramente los distintos métodos para medir el contenido de humedad en los muros, recomendando el que a nuestro entender puede ser más útil para determinar en la Catedral, tanto el contenido y distribución actual de las humedades, como la evolución que pueda irse produciendo, a fin de poder valorar en su día el grado de eficacia de las soluciones que se apliquen.

\section{Absorción de agua}

El proceso ha sido estudiado por Vos (79) en su aplicación a los monumentos.

El transporte de agua a través de los materiales porosos depende de su estructura capilar, y el proceso de absorción obedece a la ley $m=K \sqrt{t}$, siendo $(m)$ la cantidad de agua absorbida (en $\mathrm{kg} / \mathrm{m}^{2}$ ) para un tiempo ( $t$ en segundos), y $(K)$ una constante de proporcionalidad que se denomina "coeficiente de absorción de agua" $\left(\mathrm{kg} / \mathrm{m}^{2} \cdot s^{0,5}\right)$ e indica la capacidad de succión del material por efecto de las fuerzas capilares. 
Para determinar este parámetro, Vos recomienda (79) situar probetas del material en contacto con el agua, habiendo impermeabilizado previamente las otras superficies expuestas al aire para impedir la evaporación; se determina el aumento de peso a distintos tiempos

y se representan en una gráfica $m=f(\sqrt{t})$, lo que corresponde a una recta que pasa por el origen y permite el cálculo de $K$, que tendrá valores altos cuando el agua sea absorbida rápidamente y que valdrá cero para materiales impermeables.

La distribución del agua durante los procesos de absorción se efectúa de la siguiente manera: se forma un frente de agua ( $\xi$ ) que circula a través de la piedra y, cuando en este frente el contenido de agua en cada momenio permanece constante, se dice que se ha alcanzado el "contenido de agua crítico" ( $\left.\psi_{c}\right)$, y más tarde, cuando el agua alcanza un valor máximo se denomina "contenido de agua máximo" $\left(\psi_{0}\right)$. Podemos determinar este contenido máximo colocando una muestra de material seco dentro de agua y en un recipiente en el que se hace el vacío y, cuando ya no varía más la masa, se ha alcanzado el valor $\psi_{0}$.

El valor de $\psi$, se puede conocer a partir de varias curvas de secado y también basándose en que la situación del frente de agua obedece a la ley $X=A \sqrt{ } \bar{t}$, en donde $(X)$ es el desplazamiento del frente de agua (en metros) para un tiempo ( $t$ en segundos) y $(A)$ es una constante de proporcionalidad que se denomina "coeficiente de penetración de agua". Puesto que los valores de $K, A, \psi_{0}$ y $\psi_{\mathrm{c}}$ están relacionados entre sí, al conocer tres de ellos podemos calcular el cuarto con ayuda de la fórmula $A=\alpha \frac{K}{\psi_{0}}$ en donde $\alpha$ es una función de $\psi_{c} / \psi_{0}$ que se puede deducir de la gráfica.

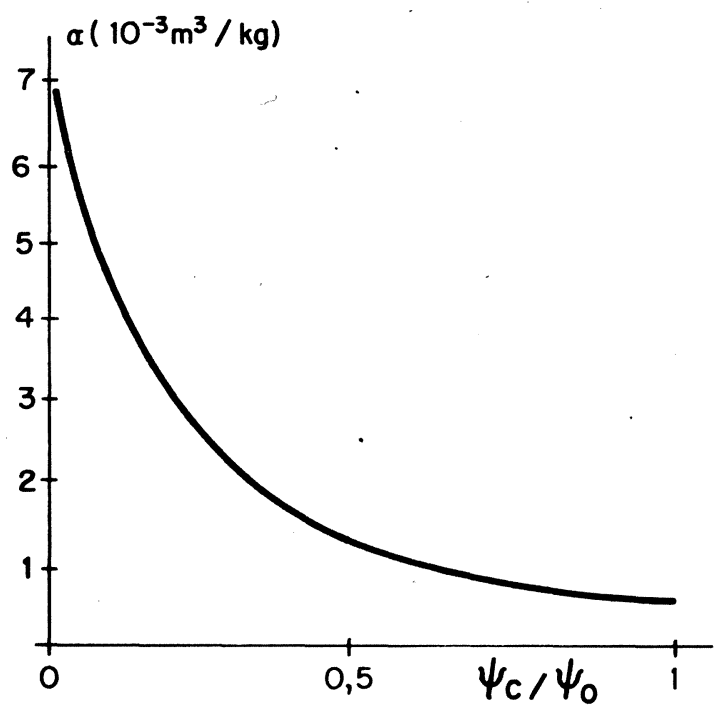

Según esto, se han podido calcular valores para calizas comprendidos entre $0,8 \times 10^{-3} \mathrm{y}$ $3 \times 10^{-3}$. Este coeficiente $A$ está relacionado con el tamaño de los poros. Usando un modelo simplificado de capilares rectos uniformes de radio $(r)$, se puede escribir que $A=$ $=\frac{\delta r}{2 \eta}$ siendo $(\delta)$ la tensión superficial, $(\eta)$ la viscosidad dinámica; la medida de (A) permite una estimación del tamaño medio de los poros y el cálculo del tiempo necesario para la penetración del agua en el material, lo que también podemos utilizar en la apreciación previa de la penetración de productos consolidantes en piedras alteradas. 
El agua penetrará en un material de espesor $(d)$ al cabo de un tiempo $(t)$ según: $t=$ $=\frac{d^{2}}{A^{2}}$ lo que supone para las tres calizas antes probadas y para un espesor de $35 \mathrm{~cm}$ unos tiempos de penetración de 3,15, 8 y 50 horas respectivamente. En estos cálculos es muy importante tener en cuenta la permeabilidad de las juntas que llegan a tener valores entre 4 y 10 veces más altos, lo cual junto con el valor de los materiales pétreos sirve para calcular la permeabilidad efectiva de los paramentos.

En muros tan gruesos y complejos como los de la Catedral de León, como son estructuras no homogéneas, con capas exteriores que retardan fuertemente la difusión del vapor, en ciertos casos pueden producirse condensaciones; una parte del material en el lado más frío puede tener un contenido de humedad próximo al nivel crítico, mientras que al otro lado que es más caliente la piedra puede estar seca o con sólo la humedad higroscópica; la situación del frente de equilibrio entre la zona húmeda y la seca $\left(X_{\mathrm{e}}\right)$ puede calcularse por:

$$
X_{\mathrm{e}}=\frac{P_{\mathrm{o}}-P_{\mathrm{i}}}{P_{\mathrm{o}}-P_{\mathrm{a}}} \cdot d
$$

siendo el tiempo necesario para que se alcance el equilibrio, el dado por:

$$
T_{\mathrm{e}}=\frac{P \cdot \psi_{\mathrm{c}}}{\delta} \cdot \frac{d^{2}}{\left(p_{\mathrm{o}}-P_{\mathrm{a}}\right)^{2}}\left[3 P_{\mathrm{o}} \rightarrow 2 P_{\mathrm{i}}-P_{\mathrm{d}}\right]
$$

y en ese momento, el "contenido medio de humedad" será:

$$
\bar{\psi}=\psi_{\mathrm{c}}-\left(\psi_{\mathrm{c}}-\bar{\psi}_{\mathrm{H}}\right) \frac{P_{\mathrm{o}}-P_{\mathrm{i}}}{P_{\mathrm{o}}-P_{\mathrm{d}}}
$$

siendo:

$P_{\mathrm{i}}=$ presión del vapor de agua en el aire interior.

$P_{\mathrm{o}}=$ presión de vapor máxima para la temperatura de la superficie interna.

$P_{\mathrm{d}}=$ presión de vapor máxima para la temperatura debajo del recubrimiento [todas las $P$ en $\left.\left(\mathrm{N} / \mathrm{m}^{2}\right)\right]$.

Tales consideraciones dependen, por supuesto, de la lluvia, y también en una cierta medida del viento. El mecanismo de penetración de la lluvia en los muros fue revisado por Ritchie y Plewes (61) y por Bierkeland (4), lo que depende del tipo de construcción y de la superficie expuesta principalmente. Generalmente se forma una película de agua sobre la superficie de la piedra que penetra en el interior del material por efecto de la succión capilar principalmente; el viento produce diferencias de presión alrededor de la construcción, según su velocidad y según la altura y la forma de la estructura, actuando con distintasi presiones en distintos puntos de los muros: aunque la influencia de la presión dei viento en el transporte horizontal del agua a través de la piedra es según Tammes y Vos (75) despreciable, puede resultar importante en el caso de que existan grietas o aberturas en juntas, etc., que ambas son frecuentes en la Catedral de León. Por otra parte, lost mu- 
ros de la Catedral situados a sotavento de la componente principal a poniente, reciben menos lluvia, lo que motiva diferencias acusadas en el contenido de agua según la orientación y las condiciones de exposición de distintos materiales. Aunque según Vos (81) la influencia de la gravedad en el transporte de humedad en los muros es muy pequeña, puede ser mayor en paredes tan gruesas como las de la Catedral; según esto, la penetración de la lluvia es más acusada en las partes bajas del muro por ser las más gruesas, lo que se ha de tener en cuenta al enjuiciar la subida del agua desde el suelo, que como hemos señalado tiene un importante papel en los problemas del claustro principalmente.

Cuando el agua del suelo sube por los muros su movimiento en el interior de la piedra se efectúa principalmente en sentido vertical. Si no existen fuerzas externas, la velocidad de transporte $(v)$ en un modelo de capilares rectos uniformes de radio $(r)$ vendría dada según Tammes y Vos (75) por:

$$
v=\frac{\mathrm{d} x}{\mathrm{~d} t}=\frac{r^{2}}{8 \eta x}\left(\rho \cdot a \cdot x \cdot \cos \gamma+\frac{2 \sigma}{r}\right)
$$

siendo $(\eta)$ la viscosidad, $(\rho)$ su densidad, $(\sigma)$ la tensión superficial, $(a)$ la fuerza de gravedad y $(\gamma)$ el ángulo que el capilar forma con la vertical.

Para, el agua que sube, $\cos \gamma=-1 \mathrm{y}$, por lo tanto:

$$
v=\frac{r^{2}}{8 \eta x}\left(\frac{2 \sigma}{r}-\rho \cdot a \cdot x\right) \text {, }
$$

por lo que cuando se alcanza el equilibrio, si se supone que no hay evaporación, $v=0 \mathrm{y}$ la altura máxima alcanzada sería:

$$
x_{\max .}=\frac{2 \sigma}{\rho a r} \text { esto es, } 15 \times 10^{-6} / r \text { (en metros) }
$$

lo que supone para materiales como la dolomita de León cuyos poros tengan un diámetro medio de unas 10 micras a pesar de la porosidad secundaria del proceso de dolomitización, la altura que puede alcanzar el agua sería de unos $15 \mathrm{~m}$; sin embargo, normalmente se alcanza el equilibrio por evaporación y la $x_{\max }$. no se alcanza, pero justifica subidas aparentemente anómalas, como las que se ven en los paramentos del claustro afectando a las pinturas murales, cuando estos recubrimientos disminuyen la capacidad de evaporación y también cuando como en nuestro caso han recibido tratamientos con resinas silicona que, aunque son permeables al vapor, dificultan en alguna medida la evaporación de los paramentos tratados.

Para poder realizar un proyecto adecuado de los problemas relacionados con esto, será necesario estudiar la composición de los muros de la Catedral que, probablemente, estarán construidos con diferentes materiales en el interior y en el exterior mediante obtención de probetas por taladro con barrenas de corona. Estas estructuras complejas hacen los cálculos muy difíciles y, por otra parte, el modelo de capilares rectos uniformes suele ser de- 
masiado simple para razonar flujos de humedad que exigen descripciones más complicadas, por lo que es necesario normalmente actuar sobre el muro directamente midiendo su contenido en humedad y su evolución con el tiempo y con los tratamientos.

\section{Tratamientos contra la humedad (14)}

Nos ocuparemos de los posibles remedios a aplicar en el claustro para evitar la subida de agua en los muros así como de los productos para la protección de los paramentos afectados por la dirección dominante de la lluvia.

Los procedimientos que se utilizan para esto pueden clasificarse en dos categorías:

a) preventivos, que tienen por objeto impedir o disminuir el acceso del agua, y

b) curativos, destinados a eliminar el agua una vez que ya está presente en los muros.

Estos sistemas son muy numerosos y constituyen una especialidad en sí mismos complicada y difícil; Massari ha revisado recientemente (47) estas cuestiones y estamos de acuerdo en afirmar que una aplicación más frecuente y sistemática de procedimientos contra la humedad aumentaría la eficacia de las restauraciones, ocurriendo en muchos casos que la sola aplicación de estos remedios y su mantenimiento regular basta para preservarlos.

Para evitar la subida de agua en los muros, Varlan (78) ha revisado los procedimientos en la antigüedad, y también han sido recordados por Gratwick (23), pudiendo destacarse el sistema de contramuro con espacio de ventilación comunicado al exterior, utilizado por los romanos y descrito por Vitrubio; aun hoy, si se quiere garantizar la eficacia de un contramuro, es necesario airearlo al exterior y no al interior como se ve frecuentemente. La reducción de la sección transversal del muro, utilizada por el arquitecto Kock (47) para proteger el fresco del Dominichino, construyendo arcos, o haciendo una zanja a todo lo largo del perímetro externo del muro incrementando así la evaporación a un nivel más bajo, como hemos realizado en el Monasterio de Ripoll entre otros casos, permiten un saneamiento eficaz además de contribuir a eliminar las aguas freáticas y servir de drenaje.

Los métodos electroquímicos, conocidos generalmente como métodos electroosmóticos son propuestos con frecuencia en los monumentos, y algunos defienden su eficacia para desecar los muros, al ver su validez industrial en la desecación de canteras de arcilla, turberas, etc. Según Stambolov y Van Asperen de Boer (73) diferentes autores observan resultados contradictorios en el tratamiento de muros, y parece que las aplicaciones favorables pueden deberse, en muchos casos, a la reducción de la sección transversal de los muros obtenida por la frecuente inserción de los electrodos de diferentes tipos y naturalezas.

Para el secado efectivo de un muro, el contenido en humedad debe ser inferior al nivel crítico, y esta diferencial exigida es mucho más estricta que en los tratamientos industriales para los que una disminución deì contenido en humedad, hasta alcanzar el $50 \%$ o más, es perfectamente tolerable.

Moraru (50) ha hecho un amplio estudio de estos métodos distinguiendo las técnicas de electrodrenaje pasivo, esto es, utilizando la inversión de las diferencias de potencial na- 
turales entre el suelo y la construcción ( 40 a $200 \mathrm{mV}$ ), y electrodrenaje activo intercalando una fuente de corriente continua de 6 a $24 \mathrm{~V}$. El mecanismo molecular de la migración electroosmótica, en medio poroso, tiene en cuenta que las moléculas dipolares del agua se orientan respecto a la pared de los poros en función del signo de su carga eléctrica, formando una doble capa eléctrica que envuelve a la columna de agua neutra del centro del capilar. Cuando se consigue invertir la polaridad - si los capilares son lo suficientemente pequeños - la columna de agua neutra eléctricamente puede seguir el flujo unidireccional del líquido a causa de su viscosidad.

El criterio para la aplicación de la electroósmosis viene definido por la relación entre el "coeficiente de permeabilidad electroosmótica" $\left(\mathrm{cm}^{2} / V \cdot s\right)$ y èl "coeficiente de permeabilidad del material a secar" (cm/s) que debe ser igual o mayor que $10 \mathrm{~cm} / \mathrm{V}$, lo que requiere poros suficientemente estrechos, mucho más que los comprendidos entre 1 y 10 micras de la dolomita de León, areniscas, ladrillos, etc. Numerosos investigadores estudian el valor de esta relación de coeficientes en distintos materiales, pero desgraciadamente los datos cuantitativos deberían ser más precisos ya que frecuentemente no concuerdan. En cuanto a los resultados prácticos de su aplicación a los monumentos, aun a pesar de la enorme experiencia de las firmas comerciales instaladoras en viviendas y edificios normales, no se han alcanzado los éxitos que cabía esperar, pese a la gran variedad de electrodos, equipos, e incluso superposición de principios como los sifones de aireación provistos de electrodos, etc.

La solución a la subida de agua desde el suelo se ha querido también resolver insertando en los muros tubos porosos con los que se pretende estimular la evaporación o incluso secar un muro que ya esté húmedo ; en este tema se integran los sifones de aireación de cerámica porosa del belga A. Knapen (37) y las múltiples variaciones comentadas por Massari y experimentadas por el C.E.B.T.P. belga (6192), entre los que merecen destacarse diversos tubos cilíndricos o semicilíndricos, en plástico o en acero inoxidable, a veces provistos de soportes en acero o cobre y conductores a tierra, que pseudo pretenden incorporar al sistema los principios de la electroósmosis. En España se pueden ver instalados en la Catedral de Murcia y en otros muchos edificios monumentales en cuyos muros continúa observándose la humedad y en cuyo interior (véase capilla de los Junterones de la Catedral de Murcia) la impermeabilización realizada en el exterior, por el empleo de piedra más compacta, ha hecho subir en el interior en más de $1 \mathrm{~m}$ la cota de la humedad ascensional, estando en peligro de destrucción una zona importante esculpida que se conservaba bien, todo lo cual es prueba de la ineficacia del procedimiento. A pesar de que las múltiples experiencias realizadas prueban que la única mejoría a veces observable procede de la reducción introducida en la sección transversal del muro por las perforaciones realizadas, siguen siendo instalados por arquitectos en nuestros monumentos.

Otra técnica de evitar la subida capilar del agua en los muros consiste en intercalar una capa de material impermeable que intercepte la difusión del agua, lo que equivale a una reducción total de la sección absorbente del muro. En principio, los procedimientos son: o inyectar productos líquidos capaces de impermeabilizar una franja del muro en todo su espesor, o seccionar el muro mediante una sierra o mediante perforaciones sucesivas (técnica de Massari) intercalando un material sólido impermeable. El Laboratorio de Investigación de los Monumentos Históricos de Francia (L.R.M.H.) (76) en colaboración con el C.E.B.T.P. de Francia ha realizado un estudio experimental con una serie de muros construidos para este fin y en los que han sido aplicados la mayor parte de los métodos propuestos, inyectando por gravedad o a presión productos tales como resinas de silicona, siliconatos, siliconato/látex, silicatos, resinas termoendurecibles, etc., así como también seccionando los muros e intercalando láminas impermeables de material plástico, mezclas bi- 
tuminosas, etc., demostrándose que sólo se obtiene una impermeabilización total al intercalar láminas totalmente impermeables, aunque con la mayor parte de los métodos de inyección también se consigue alguna disminución en la penetración de la humedad.

Por otra parte, y para proteger a los paramentos expuestos al agua de lluvia, se pueden utilizar productos hidrófobos. En este sentido, y cuando el contenido de humedad es inferior al nivel crítico, las experiencias realizadas por el C.E.B.T.P. (21) demuestran que de entre los diez mejores productos comerciales seleccionados, cinco se han revelado totalmente ineficaces y los otros cinco, a base éstos de resinas silicona, han suministrado una protección significativa. Como veremos más adelante al estudiar las resinas de silicona, esto se debe a la propiedad de ser impermeables al agua líquida y permeables al vapor de agua. Cuando el muro contiene humedad por encima del valor crítico, estos tratamientos sólo encubren los efectos de la humedad, disminuyen la evaporación y pueden ser causa de un mayor ascenso del agua así como de la salida por el interior, como tenemos en los tratamientos realizados en la Catedral de León en varias ocasiones en el claustro y pórtico occidental, en los últimos años.

\section{PROCESO DE DESALACION}

\section{Penetración del agua a través de la superficie de la roca tratada con resinas de silicona}

Para conseguir que el agua penetre, atravesando la capa siliconada, o se elimina esta resina o se hace descender el valor de la "tensión superficial" del agua que es quien determina si, en la interfase de contacto entre el agua y la silicona, la penetración es o no posible.

La tensión superficial de estos productos orgánicos (mayor es el de los aceites, disolventes orgánicos y otras sustancias no específicamente polares), es de aproximadamente unas 30 dinas $\cdot \mathrm{cm}^{-1}$, frente al valor para el agua de 72 dinas $\cdot \mathrm{cm}^{-1}$. Por esto, para que el agua pueda penetrar en los poros hidrofugados, la fase líquida debe mojar a la fase sólida y se ha de formar una interfase entre el agua y la superficie a tratar: cuando es alta la del líquido respecto al sólido, como en nuestro caso, el agua forma gotas más o menos esféricas siendo mínimo el contacto entre las dos fases. A fin de disminuir el valor de la tensión superficial del agua se le puede añadir un agente tensioactivo, lo que permite modificar sensiblemente sus características de superficie, ya que un buen mojante añadido al agua en la concentración de 0,01 \% hace disminuir la tensión superficial por debajo de 30 dinas $\cdot \mathrm{cm}^{-1}$ que es aproximadamente el valor que necesitamos.

La elección del detergente a emplear, de acuerdo con las variables de nuestro problema, nos lleva a plantear las siguientes consideraciones.

Desde el punto de vista de su composición química, la molécula de agente tensioactivo comporta una parte hidrófila y otra parte lipófila: la unión en el mismo sistema de un principio oleosoluble y de otro hidrosoluble, conduce al carácter particular de estas sustancias. Por eso, entre las fases líquida y la sólida se desliza una capa monomolecular del agente tensioactivo, formada a partir de las reservas de la fase líquida, que se absorbe en la interfase agua-silicona, proyectando la cadena hidrocarbonada hacia la resina y los 
grupos polares hacia el agua, resultando una disminución de la tensión interfacial con lo que la fase agua se esparce sobre la fase silicona.

Estos agentes tensioactivos se clasifican en cuatro grupos, tomándose como característica de diferenciación entre ellos la carga del ion tensioactivo en disolución acuosa.

El grupo más importante cuantitativamente es el de los tensioactivos ANIONICOS que comportan grupos funcionales con carga negativa. En nuestro caso no podemos emplearlos dada la existencia de iones $\mathrm{Ca}^{2+}$ y $\mathrm{Mg}^{+}$tanto en la dolomita como en las sales solubles, con los que reaccionaría el tensioactivo formando jabones cálcicos y magnésicos, lo que "cortaría" la disolución formando una pasta.

Los CATIONICOS proporcionan grupos funcionales con carga positiva. Tampoco pueden ser empleados porque, al estar cargadas las piedras negativamente por lo general, son absorbidos rápidamente sobre las paredes de los poros, no contribuyendo al fin para que han sido programaidos.

Los ANFOTEROS tienen posición intermedia, positiva o negativa, según el $\mathrm{pH}$ del medio, por lo que en nuestro caso no tienen un interés técnico.

Para nuestro caso, son los NO IONICOS los más útiles. No dan ningún ion en disolución sino que en la parte hidrófila tienen grupos hidróxilo o etóxilo. No tienen pues las desventajas de los anteriores y sí mayor capacidad de mojado.

Para el tratamiento hemos seleccionado el agente tensioactivo Lissapol fabricado por ICI, ampliamente utilizado en problemas de conservación.

\section{Utilización de pastas absorbentes}

Plenderleith (55) recomienda el empleo de pasta de papel húmeda para extraer las sales contenidas en los objetos de piedra o de cerámica que no pueden desalarse por inmersión en agua como es nuestro caso, tanto por el gran tamaño de las piezas como por la existencia de restos de policromía en la que el yeso es uno de los componentes.

La descripción pormenorizada de los diferentes métodos y productos para la eliminación de las sales solubles en objetos de piedra fue realizada por Sneyers, R. V. y de Henau, P. J. (71) describiendo los distintos pasos de fijación, extracción por inmersión en agua, con pulpa de papel, circulación forzada a través de la piedra, utilización del agua caliente $\mathrm{y}$, finalmente, el tratamiento de bloqueo de las sales con cera cuando éstas no pueden ser extraídas.

A nuestro parecer, la introducción de pastas absorbentes formadas con arcillas especiales finamente molidas en la conservación de bienes culturales se debe a Mora (49) quien comunicó, en 1972, la utilización de la atapulgita en los procesos de desalación de pinturas murales hechas al fresco.

Un estudio muy profundo de todos los parámetros implicados en los procesos de desalación, razonando primero los principios conectados con los materiales, el agua, los iones 
y todas las fuerzas que los relacionan, sobre modelos teóricos y a nivel de experiencias de laboratorio, para pasar seguidamente a la realización práctica de las soluciones, se debe a Jedrzejewska (32) y ha de ser tenido en consideración totalmente en las distintas particularidades de la realización práctica de los trabajos, por lo que su resumen simplificado no es ahora posible.

En nuestro caso, hemos seleccionado una mezcla de talco: caolín: sepiolita $(1: 1: 2)$ a la que se añade agua con $0,01 \%$ de lissapol hasta consistencia pastosa. Se busca un color muy blanco de la pasta para hacer más distinguibles los residuos que puedan quedar sobre la superficie irregular de las obras, a fin de proceder a su eliminación minuciosamente. Este afán de eliminación total se debe a que junto con los polvos de esta masilla se encuentran las sales que nos proponemos extraer, principalmente.

\section{SELECCION DEL PRODUCTO PARA EL TRATAMIENTO FINAL DE CONSOLIDACION Y PROTECCION}

\section{Generalidades}

Para consolidar y proteger la superficie de estas obras hechas en piedra, se podrían utilizar productos orgánicos o inorgánicos.

Un sector de los restauradores defiende por principio el empleo de compuestos inorgánicos, haciendo hincapié en conceptos de tipo filosófico que les impiden mezclar la piedra con lo orgánico.

Para muchos especialistas resulta preferible el empleo de compuestos orgánicos, más versátiles y de aplicación más adaptable a las particularidades específicas de cada problema.

El problema fundamental que caracteriza la aplicación de unos u otros es que, por lo general, los resultados conseguidos son poco satisfactorios. Cuando los problemas se pretenden resolver por la sola aplicación de un producto más o menos sofisticado, pretendiendo ser una panacea que resuelva al mismo tiempo los problemas de debilitamiento de la piedra y las causas del mal, ya sean sales, contaminantes, humedades, etc., el error fundamental se encuentra en el principio de operación que pretende actuar a tontas y a locas careciendo de un diagnóstico justificado y de una terapéutica razonable.

En cuanto a los productos, por ellos mismos que es el objetivo de este apartado, y cuya utilización se integrará dentro del contexto más amplio que planteamos en esta memoria, los problemas nacen tanto de la naturaleza intrínseca de estos compuestos como de su insuficiente penetración en el material pétreo poroso.

Desde antiguo, y para la consolidación de las superficies se ha intentado la aplicación de capas adhesivas a base de aceite de lino cocido, resinas naturales, lechada de cal, silicatos alcalinos, fluosilicatos, fluoruros, siliconas, disoluciones de sales de bario, etc. La protección de las piedras también se intentó por impregnación con disoluciones reales o coloidales de numerosos productos, de la mayor parte de los citados y también de ceras, para- 
finas (fundidas con calor), agua de cal alternada con caseína, resinas vinílicas, resinas acrílicas, resinas epoxídicas y de poliéster, jabones metálicos como los estearatos de aluminio o de zinc, ésteres silícicos, etc.

Aplicados en exteriores, sus efectos no son generalmente muy duraderos. Una vez en el interior de los poros unas disoluciones deben perder el disolvente, otras deben reaccionar con productos introducidos más tarde, las soluciones reales tienden a acumularse en el frente de evaporación y las dispersiones coloidales pueden romperse al entrar en contacto la fase dispersa con los elementos salinos presentes o con las paredes de los poros que por su carga eléctrica son capaces de provocar la floculación, lográndose en estos casos una consolidación de la superficie solamente, lo que es poco útil e incluso perjudicial cuando quedan restos de sales o humedad en el interior de la piedra, favoreciéndose la formación de estalladuras, etc.

En este apartado nos ocuparemos exclusivamente de los productos de mayor eficacia intrínseca, prescindiendo de las otras variables relacionadas con los mecanismos de alteración presentes y que suponemos resueltos en fase previa, así como de otros varios productos como mezclas de cal, jabones metálicos, "goma-laca", barnices naturales, aceites secantes, etc. que son inadecuados para nuestro caso, "a priori".

Es necesario anotar que la mayor parte de los productos, y en especial los orgánicos, modifican más o menos el aspecto de las piedras tratadas, lo que hace difícil que se puedan recomendar indiscriminadamente para todas las piedras. Este tema viene siendo estudiado por los especialistas del color, que insisten en que de los tres parámetros que caracterizan el color propiamente dicho (longitud de onda dominante, pureza y brillo), estos tratamientos no modifican en absoluto al primero, por lo que no puede hablarse de una auténtica modificación del color, sino más bien de alguno de los factores que contribuyen a definirlo. En lo que respecta a las soluciones prácticas de este problema, sabemos que la naturaleza de la roca es un importante factor por el cambio de aspecto, por el elevado índice de refracción de estos compuestos. Winkler (86) ha propuesto este año un método simple de determinación del color y su variación al aplicar productos, utilizando medidas comparativas con un fotómetro entre la piedra tratada y la no tratada, usando como referencia los cartones grises Kodak y la escala de colores Munsell. En nuestro caso, un método aún más simple, consistente en comparar una piedra de León limpia e impregnada con el producto seleccionado, con otra limpia y sin impregnar, indica que el cambio fundamental es de aspecto al ser limpiada más que por el producto, lo que se justifica por el alto contenido de esta dolomita en arcillas y minerales de hierro.

Un tema muy controvertido es el que se relaciona con la alterabilidad de los materiales consolidantes por acción de la luz. La resistencia de diferentes barnices a las radiaciones visibles y ultravioletas ha sido estudiado muy detenidamente en su aplicación a los barnices de la pintura, los cuales por estar totalmente en superficie, reciben completamente la acción destructiva de las reacciones de oxidación fotocatalizada; aunque todos estos materiales son alterables por la luz, tanto una capa de silicato de etilo como una resina acrílica, son por regla general estos compuestos acrílicos los que mejor se comportan a la acción de la luz.

Por otra parte, es necesario tener en cuenta que la acción de las reacciones catalizadas por la luz sólo se produce allí en donde hay luz, lo cual en nuestro caso no sucede en el interior de los poros de la roca los cuales, a pocas micras de profundidad, son totalmente opacos en muchos casos. En nuestra experiencia, materiales que se conservan en ausencia 
de radiaciones visibles y ultravioleta, se conservan muy bien casi indefinidamente: este término que quiere valorar etapas de casi trece mil años, lo utilizamos en base a la existencia de resina de ámbar conservada en el techo de las pinturas de Altamira, así como a un colorante orgánico violeta también utilizado allí por el hombre prehistórico (7).

\section{Productos de consolidación de naturaleza orgánica}

Nos referiremos exclusivamente a las ceras y a los ésteres acrílicos y de siliconas.

Aunque existen numerosos inconvenientes que restringen teórica y prácticamente el empleo de ceras y parafinas para el tratamiento de las piedras, se usan muy a menudo. En España, Sanmartín (65) ha consolidado granitos en Galicia, especialmente el Pórtico de Platerías de la Catedral de Santiago de Compostela, utilizando una mezcla de cera de abejas y azufre que se extiende sobre la roca previamente calentada con un soplete; este método que se inspira en el tradicional utilizado por los canteros gallegos para pegar fragmentos de granito, también lo ha aplicado a areniscas como algunas laudas sepulcrales del Monasterio de Poblet y unas pruebas en la Portada de Ripoll. El método empleado no consigue resultados satisfactorios en ninguno de los casos realizados.

Una forma más correcta de utilización de la cera de parafina fue la realizada en la protección contra los contaminantes atmosféricos de la Aguja de Cleopatra, en Londres: Burgess y Schaffer (5) señalan que se hizo una disolución al $10 \%$ en White Spirit que se aplicó sobre la piedra seca en dos veces consecutivas y, una vez evaporado el disolvente, se calentó la superficie con un soplete para derretir la cera en las fisuras. Sneyers y de Henau (71) consolidaron restos escultóricos cargados de sales, bloqueando éstas con una mezcla de dos partes de cera de abejas y ocho partes de cera de parafina fundida con calor y que se hace gotear sobre la piedra calentada con infrarrojos, siendo la cantidad de cera consumida un índice de la calidad conseguida con el tratamiento, pues el objetivo a conseguir es aislar los cristales de sal dentro de la masa de cera. También nos informan de la utilización de las ceras sintéticas microcristalinas, como las fabricadas por Astor Boiseller, de Londres, con el nombre de Cosmolloids y que presentan ventajas indudables por tener una amplia variedad de puntos de fusión, no atraer tanto el polvo, etc. En otros casos, lo que se ha aplicado es una mezcla de parafina y polietileno mediante pistola.

Recientemente, un proyecto de una firma comercial ha propuesto para la fachada de San Marcos, en León, como fase final del tratamiento, la aplicación de cera microcristalina siendo también la piedra una dolomita de Boñar.

Dentro de la amplia gama de productos que se denominan resinas sintéticas preseleccionamos únicamente dos grandes grupos: las acrílicas, ya sean polímeros o monómeros y las de silicona, dejando al margen todos los demás productos de siliconatos, resinas epóxicas, poliacetatos de vinilo, etc. que ya sea por la producción de sales como sucede con los siliconatos o por no aportar condiciones mejores que los acrílicos, no presentan ninguna característica de especial atención para nosotros en el caso presente.

De los ésteres acrílicos, han sido utilizados en muchísimos casos los tres principales de metil, etil, o butil metacrilato. El Paraloid B-72 o el B-82 al $5 \%$ en Tolueno (polibutilmetacrilato) ha sido utilizado con éxito por Mora (54) en la consolidación de frescos y, por 
extensión y también con éxito, en la consolidación de numerosos tipos de piedra, entre los que destacamos las columnas del convento de San Bernardo, en el Cuzco, realizado por nosotros mismos (12). Esta resina se está constituyendo en casi una panacea entre los restauradores, que también la utilizan para fijar la superficie de la pintura, engrasar temples, formar parte de barnices de cuadros, consolidar maderas y otros productos porosos, barnizar objetos de plata para evitar el ennegrecimiento por el $\mathrm{SH}_{2}$ atmosférico, etc. Para el tratamiento de rocas porosas, nosotros preferimos y venimos utilizando, desde 1965 con éxito en todos los casos estudiados (8), un producto mezcla de dimetil acrilato y etilmetacrilato denominado Bedacryl $122 \mathrm{X}$ y fabricado por Imperial Chemical Industries como una disolución al $40 \%$ de resina sólida en Tolueno.

Una importancia grande debe atribuírsele al disolvente que se utilice. Domalowski y Leheman (17), han estudiado el mecanismo de acumulación de las resinas en las superficies de evaporación como una función de las siguientes variables:

1) Volatilidad de los disolventes.

2) Temperatura de secado.

3) Tiempo de secado.

4) Concentración de las disoluciones.

5) Diferentes resinas de distinta naturaleza.

Las conclusiones que establecen pueden resumirse en:

A) Disoluciones de polimetacrilato de butilo en una docena de disolventes cuyas volatilidades varían entre 2,1 y 163 respecto a la del éter etílico, demuestran que, excepto para el White Spirit, en todos los demás se produce una migración similar hacia la superficie de evaporación.

B) En White Spirit, las disoluciones de polimetacrilato de butilo a temperaturas comprendidas entre 20 y $100^{\circ} \mathrm{C}$ se depositan siempre uniformemente en toda la superficie e interior de la muestra.

C) Al disminuir la velocidad de evaporación por medios externos, mejora la distribución en el seno de la muestra de polimetacrilato de butilo disuelto en Tolueno.

D) La concentración de polimetacrilato de butilo, en White Spirit, comprendida entre el $5 \%$ y el $20 \%$, demuestra que la concentración influye en la migración, pues al $5 \%$ el corazón de la muestra no queda consolidado y con el $10 \%$ sí lo está.

E) Estudiando el comportamiento de disoluciones al $10 \%$, en White Spirit, de polimetacrilato de butilo, polimetacrilato de etilo, polimetacrilato de metilo, poliacetato de vinilo, policiclohexanona y colofonia y, después, en acetato de metilglicol como disolvente se ve que todas las resinas se comportan igual, quedando bien distribuidas en profundidad con el White Spirit y quedando todas en superficie con el otro disolvente. 
Recientemente, Winkler y Clifton (87) han estudiado también la acción de los disolventes sobre los productos protectores de la piedra. En términos prácticos aceptamos que los mejores resultados se consiguen con impregnaciones lo más profundas que sea posible (inmersión, vacío, etc.) de resinas a la concentración del $10 \%$ en White Spirit y con un proceso de secado tan lento como se pueda.

Hace pocos años, e inspirándonos en los trabajos realizados en Bruselas por Sneyers para la desalación de una mastaba egipcia con restos de policromía, hicimos un proyecto de trabajo para el tratamiento de la "Dama de Baza" (10), y en el que programamos el empleo como fijativo de la superficie de una disolución diluida de un nylón modificado denominado Calaton C.A. (fabricado por I.C.I.) capaz de dar en disoluciones alcohólicas películas muy flexibles y disconinuas que penetran bien, y fijan el material disgregado sin obturar los poros a fin de permitir otras fases posteriores del tratamiento; revelaciones recientes hacen ver que quizás no constituya esto una prueba verdadera de empleo del producto mencionado: los restauradores que allí trabajaron dicen que lo publicado no se ajusta a lo que realizaron, con lo que demuestran que lo que realizaron no se ajustó - hurtándose a la vigilancia - a lo proyectado, con lo que al parecer la fijación de esta superficie se debe más a la "gelatina" que utilizaron que al nylón que se recomendó como producto más idóneo. Pese a las inadecuadas características de la gelatina, no tememos demasiado por la correcta conservación de esta policromía, ya que se conserva dentro de una sala del Museo Arqueológico Nacional y con un clima controlado y más bien seco.

La impregnación con monómeros que después polimerizan en el interior de los poros tiene grandes ventajas. Los monómeros acrílicos, debido a su baja viscosidad de unos 0,6 centipoises (las resinas epóxicas de baja viscosidad como el Araldit CY232-HY951 tienen 650$750 \mathrm{cp}$.) penetran profundamente y endurecen sin peligro de que se acumulen en las superficies de evaporación, rellenando totalmente los poros que impregnan.

Para polimerizar estos compuestos olefínicos existen varios procedimientos. El más utilizado es por polimerización de radicales en cadena con peróxidos como iniciadores; en estos procesos la mezcla en reacción se debe calentar para formar una cantidad suficiente de radicales libres por disolución de los peróxidos que, como por ejemplo el peróxido de isobutilo o el di-isopropilperoxidicarbonato, se disocian a la temperatura ambiente, por lo que éstos pueden resultar explosivos y son de difícil manejo. Para acelerar la polimerización se puede calentar el peróxido pero, en nuestra experiencia, al calentar en estufa el de benzoilo para también desecarlo, se produjo una explosión que, por tener poco aire, originó una gran masa de humo, lo cual resulta peligroso. Para acelerar la polimerización a temperatura ambiente, se eñaden activadores que provocan la disociación de los iniciadores de peróxido y para esto sirven numerosas sustancias: para los peróxidos de acilo, como el peróxido de benzoilo, que empleamos frecuentemente en nuestro caso, se emplean aminas terciarias y para los hidroperóxidos como el de metil-etil-cetona, se utilizan compuestos organometálicos como los octoatos o los naftenatos de cobalto frecuentes en la formulación de los poliésteres.

Munnikendam (51) ha comprobado la acción de diferentes combinaciones de iniciadores para radicales alifáticos, a temperatura ambiente, capaces de activar la polimerización de compuestos acrílicos, obteniendo los mejores resultados con el peróxido de benzoilo y la dimetilparatoluidina, añadiendo al monómero $2 \%$ del primero y $0,6 \%$ de la segunda, con lo que al cabo de $2 \mathrm{~h}$ a temperatura ambiente, empieza a aumentar la viscosidad, recomendando que se cubra el objeto impregnado con una hoja de papel de aluminio para evitar la evaporación, y lo mismo ha recomendado recientemente Witte y Mathot del IRPA. de Bruselas, quienes utilizan azo-bis-iso-butironitrilo como iniciador del monómero (88). 
Durante el tratamiento de consolidación, que en 1970 aplicamos a unos leones ibéricos de piedra procedentes de las excavaciones de Pozo Moro en Albacete y que se conservan en el Museo Arqueológico Nacional de Madrid, la utilización de este procedimiento de polimerización de monómero metacrílico nos ocasionó serias dificultades debido a que, en el mecanismo de endurecimiento, es muy sensible al oxígeno del aire que llegaba a retrasar y, a veces, a impedir la polimerización. Para evitar esto, aplicábamos sobre la superficie impregnada una disolución de Bedacryl que actuaba como un barniz provisional impidiendo el contacto entre el monómero y el aire, lo que da buenos resultados. Esto también puede lograrse cubriendo el objeto impregnado con una pasta de glicol espesado, con cera, o por inmersión en agua, así como por la utilización de catalizadores de derivados del borano o utilizando monómeros difuncionales.

La utilización de mezclas de monómeros acrílicos y de poliéster también suministra resultados útiles en algunos casos, aunque lo más frecuente sea la dilución del monómero con estireno. En esto, científicos relacionados con la Energía Atómica han iniciado un programa denominado NUCLEART (52), en la que hacen polimerizar una mezcla de poliéster y estireno, en particular el "Stratil A228" de Rhône-Progil en Francia, metido en el interior de los poros de la piedra mediante irradiación con radiación Gamma de una bomba de Co-60, lo que permite impregnar cómodamente losi materiales al vacío y sin riesgos de endurecimiento imprevisto, eliminar los excesos, conservar el gran volumen de resina necesario para la inmersión en tanque de las giandes piezas, mejorando notablemente las características mecánicas y tecnológicas de los materiales tratados, aunque queda por resolver el difícil problema del comportamiento térmico del conjunto piedra-polímero en la reacción exotérmica de polimerización de los monómeros, así como los fenómenos de contracción de la resina en la formación del sólido.

Por otra parte, también se han utilizado para la consolidación de piedras las resinas epoxídicas, tanto en monómeros de alta viscosidad como en los de baja viscosidad, pero su utilización no la discutiremos aquí pues las rechazamos por principio y experiencia en casos como el que ahora nos ocupa.

Las resinas de silicona se utilizan frecuentemente para hidrofugar superficies expuestas al agua de lluvia. Gérard ha comunicado recientemente (21) de acuerdo con el IRPA de Bruselas, las experiencias realizadas con diferentes productos comerciales, utilizando únicamente resinas de silicona y prescindiendo totalmente de los siliconatos, como es lógico, por la producción de sales que originan. Estas resinas, por su débil tensión superficial, penetran fácilmente en la piedra y tapizan las paredes de los poros, pero la película formada es permeable a los gases y al vapor de agua, lo que permite que la piedra "respire". El estudio previo de los productos suministrados por una docena de firmas comerciales indica que todos ellos pertenecen al grupo de las metilsiliconas, pero se aprecia que al calentarlas durante 24 horas a $50^{\circ} \mathrm{C}$ y después 4 a $100^{\circ} \mathrm{C}$, unas continúan siendo viscosas mientras que otras endurecen en masa homogéneas y, otras aún, endurecen y se fragmentan en gránulos pseudocristalinos. La experiencia demuestra que una resina, viscosa y otra dura, de las ensayadas, han dado buenos resultados después de 4 años de exposición, mientras que aquellas que se descomponen con el calor desaparecen en poco tiempo sus características hidrofugantes.

Teniendo en cuenta el carácter de inercia química de las siliconas absorbidas sobre un material, que debe ser silicatado, pues sobre las calizas sólo se logra una adsorción de tipo físico sin conseguirse ningún ligazón de valencia de tipo primario con la superfcie de la roca, la impermeabilidad que suministran pu „de durar bastante. 
Respecto a la eficacia de las siliconas en aspectos diferentes a la protección contra el agua líquida, debemos remarcar que: la alcalinidad las destruye rápidamente y esa alcalinidad puede proceder a veces del propio material húmedo, como es la caliza o los morteros de cal, o la acción del agua de mar, así como que no actúan como protección frente a los gases ácidos contaminantes de la atmósfera ni contra las sales de la piedra por permitir la salida del vapor de agua, lo que hace que tras ellas se acumulen las sales produciendo estalladuras y costras. Por su carácter hidrofugante y por reducir el contenido de humedad en los materiales por debajo del nivel crítico, se consideran útiles para evitar el crecimiento de organismos vegetales como plantas y líquenes, pero recientemente Jaton (31) ha informado que no suministran protección apreciable contra los microorganismos.

Resulta también de interés las experiencias de utilización conjunta de resinas acrílicas y de resinas silicona, así como de las siliconas con el silicato de etilo o de los monómeros epoxídicos de baja viscosidad con el silicato de etilo que hace bajar la viscosidad aún más, todo lo cual está recogido con detalle en las ponencias de Bolonia editadas por RossiManaresi (64) entre otras recopilaciones de los últimos años.

\section{Comentario final}

Para determinar los medios de protección, que en cada caso son los necesarios estrictamente, se han de estudiar los problemas con espíritu científico, desechando las nebulosidades empíricas y las tautologías para llegar a elaborar diagnósticos precisos y claros.

Somos conscientes de las dificultades que entraña la realización de este tipo de estudios que son, por esencia, multidisciplinarios y, por esto, se trata de concentrar los esfuerzos en dos líneas principales de acción: según la primera, se pretende recopilar cuanta información científica y técnica se desprende de estudios muy profundos, conducidos sobre un monumento, en concreto, como es el caso de Borobudur entre otros actualmente, y de acuerdo con la segunda línea, se quiere recoger cuanta información — salida de las distintas disciplinas científicas y técnicas- pueda colaborar al estudio para la conservación de la piedra en exteriores, planteando en muchos casos programas muy específicos. En este segundo camino y utilizando el potencial establecido para investigaciones geológicas, materiales de construcción, etc., se han realizado bastantes reuniones internacionales que, con frecuencia, confrontan a los más notables especialistas a fin de analizar el estado actual de los avances en cada campo.

A partir de 1965, fecha en la que contribuimos a este esfuerzo común internacional con el 1. ${ }^{\text {er }}$ Simposio Internacional de Madrid sobre Alteración y Conservación de la Piedra en los Monumentos, se han presentado trabajos de primerísimo orden en los Coloquios de Bruselas de 1966 y 1967-68; addemás de las reuniones generales del Comité del ICOM para la Conservación con su Grupo de Trabajo "piedra", la reunión del I.I.C. de Nueva York, en 1970 y otras muchas, siendo las más recientes: 1969, Bolonia, Centro per la Conservazione delle sculture all'apertoo; 1971 también Bolonia; 1972 La Rochelle (Centre de Recherches et d'Etudes Oceanographiques; 1975 en Bolonia y en La Rochelle; 1976 en Atenas, National Technical University Laboratory of Physical Chemistry; 1978 París, UNESCORILEM, entre las más principales.

La creación en 1972, en el seno de la RILEM, del Grupo de Trabajo 25 PEM (Protection des Monuments en Pierre Naturelle, o, Pierre Erosion Monuments), con el fin de buscar 
métodos experimentales para examinar las alteraciones de las piedras calizas y determinar la eficacia de los métodos de tratamiento, tiende a establecer ensayos normalizados que permitan sustituir las observaciones subjetivas por datos cifrados sobre diversos parámetros tales como: adherencia, coeficientes de permeabilidad al agua y al vapor de agua, capilaridad, porosimetría, succión (microporosidad), heladicidad, cristalización de sales, curva de evaporación, densidad aparente, ensayos mecánicos, velocidad de propagación del sonido, medida de la frecuencia de resonancia fundamental, etc.

A nuestro parecer, el estado actual de nuestros conocimientos y actuaciones en el dominio de la conservación de la escultura lítica en exteriores, puede caracterizarse por una serie de avances profundos en parcelas relativamente aisladas, por lo que resulta conveniente reforzar las líneas de trabajo que permitan establecer los nexos pluridimensionales que faltan.

Sin pecar exageradamente de optimistas, pero buscando las soluciones que las ciencias nos ofrecen dentro de la enorme dificultad que el conocimiento de tan amplios horizontes plantea, hoy por hoy es posible la conservación de la escultura lítica exenta tanto en nuestras catedrales como en las antiguas ciudades de los Mayas, haciendo diagnósticos buenos y compensando con calidad operatoria los márgenes lógicos de incertidumbre y de desconfianza que nacen del enfrentamiento puramente reflexivo con tan árduos problemas.

\section{B I B L I O G R A F I A}

(1) Berthollet, C. L.: "Essai de statique chimique", 2 vols. París (1803), lère partie: "Des limites de la combinaisson", cap. III "De l'efflorescence", vol. I, págs. 403-409.

(2) Bertolaccini, M. A., Cerquiglini, S., Fassina, V. \& Torraca, G.: "Study of some gaseous and particulate polluants in the atmosphere of Venice (1972-1973) and their effect on the deterioration of Istrian stone"; International Centre for the Study of the Preservation and the Restoration of Cultural Property, Roma 1975.

(3) BeSCHEL, R. E.: "Dating rock surfaces by lichen growt and its application to glaciology and physiography (Lichenometry)"; en Geology of the Artic. Proceeding of the Firts Int. Symp. Art. Geology; vol. 2, págs. 1.044-1.062.

(4) BIERKELAND, O.: Norwegian test methods for rain penetration through masonry walls"; Symposium on masonry testing ASTM, Special Technical Publication, n. ${ }^{\circ} 320$, Philadelphia 1963, págs. 3-5.

(5) Burgess, S. G. and Shaffer, R. J.: "Cleopatra's needle”; Chemistry and Industry, 1952, pág. 1.026.

(6) Butтerqwoth, B.: "Some striking exampes of eflorescence on stone"; VII Intern. Congr. of Ceramics, Londres 1960.

(7) Cabrera Garrido, J. M. : "Les matériaux de peinture à Caverne d'Altamira"; 5th Triennal Meeting. Committee for Conservation. ICOM. Zagreb, 1978.

(8) Cabrera Garrido, J. M.a : "Alteración y Conservación de materiales pétreos en los Monumentos"; Tesis Doctoral, Universidad Autónoma de Madrid, 1973.

(9) Cabrera Garrido, J. M.a. "La Conservation du Portail de Ripoll"; ICOMOS, Monumentum, vol. I, págs. 83-102, París, 1967.

(10) Cabrera Garrido, J. M. : "Conservación de una escultura Ibérica del s. IV a J. C."; Informes y Trabajos del I.C.C.R. vol. 12, Madrid, 1972. 
(11) CABReRa GarRido, J. M.a.: "La Conservación de la Portada de Ripoll: datos complementarios"; Bulletin de l'Institut Royal du Patrimoine Artistique "in Memorial Paul Coremans", vol. XV, págs. 40-50, Bruselas, 1975.

(12) Cabrera Garrido, J. M.a : "Conservación de la piedra en los Monumentos del Cusco, Perú"; Misiones UNESCO, Proyecto Per-71-539, 1976-1977.

(13) Clements, F. E. and Shelford, V. E.: "Bioecology"; John Wiley, pág. 415. New York, 1939.

(14) "Conference on the Problems of Moisture in Historic Monuments", ICOMOS, Roma 1967.

(15) Cooper, R. and Rudolf, E. D.: "The role of lichens in soil formation and plants succesions"; Ecology, vol. 34, págs. 805-808.

(16) Degranges, P., Greffard, J. et Prevosteau, J. M.: "Etude des propiétés sorptives du $\mathrm{SO}_{2}$ atmosphérique ser les matériaux calcaires”; Colloque International UNESCO-RILEM, 3.1. París 1978.

(17) Domalowski, W. et Leheman, I.: "Recherches sur l'affermissement structural des pierres au moyen de solutions de résines thermoplastiques"; The Treatment of Stone, pág. 225, Bolonia, 1972.

(18) Franco MAta, M. A.: "Escultura Gótica en León", Madrid-León, 1976. Tesis Doctoral, Universidad Complutense de Madrid, 1974.

(19) Garcia de la Foz, J.: "Crónica de la Provincia de León”; Crónica General de España, pág. 66, Madrid, 1867.

(20) Gerard, R.: “Trois méthodes d'essai de gélivité récement normalisées en Belgique”; Colloque International UNESCO-RILEM, 3.2. París, 1978.

(21) Gerard, R.: "Etude de la protection des pierres calcaires au moyen de résines silicones"; The Treatment of Stone, Bolonia, 1972.

(22) Gomez Moreno, M.: "Catálogo Monumental de España, Provincia de León, 1907-1908”; Vol. I, páginas 222-224, Madrid, 1925.

(23) Gratwick, R. T.: "L'humidité dans le bâtiment: causes et rémedes"; Edit. Eyrolles, París, 1970.

(24) HALE, M. E.: "Lichen Handbook"; Smithsonian Institution, Washington, 1961.

(25) Henderson, M. E. and Duff, R. B.: "The release of metallic and silicate ions from mineralls rock and soils by funjal activity"; Journal of Soil Science vol. 14, n.o 2, 1964, págs. 236-246.

(26) Hirschwald, J. de Z.: Prek. Geol. (1908), n.o 16, pág. 257, citado por KIESLINGer, A.: "Les principaux facteurs d'altération des pierres à bâtir"; ICOMOS Monumentum, vol. II, pág. 61, 1968.

(27) Honeyborne, D. B. and HARRIs, P. B.: "The structure of porous building stone and its relation to weathering behaviour"; Evert, D. H. \& Stone, F. S. "The Structure and Properties of porous materials", Butterworths, pág. 343, Londres 1958.

(28) HUeCK VAN DER Plas, E. H.: The microbiological deterioration of porous building materials"; Central Laboratory TNO for Building Materials and Structures, n. $6 / 67$, Delft, Holanda 1967.

(29) I.C.O.M.O.S.: "Conference on the Problems of Moisture in Historic Monuments"; pág. 332, Roma 1967.

(30) IÑIgUez HERRERo, J.: "Alteración de calizas y areniscas como materiales de construcción"; Ministerio de Educación Nacional, Tesis Doctoral. Universidad Complutense de Madrid, Madrid 1961.

(31) Jaton C. et ORIAL, G.: "Ecologie microbienne de murs expérimentaux en pierre calcaire et traitement indirect avec des hydrofuges"; Colloque International UNECO-RILEM 4.5. París, 1978.

(32) JeDRzejewsKa, H.: "Removal of soluble salts from stone"; ICC Conference on Conservation of Stone and Wooden Objects, págs. 19-33, New York, 1970. 
(33) KauffmanN, J.: 'Rôle ues bactèries nitrifiantes dans l'alteration des pierres calcaires des Monuments ; Comptes Rendues Académic Sciences, 234, pág. 2.395, 1952.

(34) Kauffmann, J. et Toussaint, P.: "Corrosion des pierres: nouveles expériences montrant le rôle des bactéries nitrifiantes dans l'altération des pierres calcaires des Monuments"; Corrosion et Anticorrosion, Vol. 2, pág. 240, 1954.

(35) KELLeR, E., BALgOARd, T. and REesman, P.: "Dissolved products of artificialy pulverized silicate minerals and rocks"; Journal Sedimentary Petrographie, vol. 33, pág. 191, 1963.

(36) KIEsLINGER, A.: "Ein Beitrag zur Marmorverwiterung. Erneuerungen am Wierner Postsparkassengebaude"; Osterr, Bauzeitung, tomo 9, pág. 269,Viena 1933.

(37) KNAPEN, M. A.: "Le problème de la conservation des materiaux des habitations et des Monuments"; Revue des Entrepreneurs de Belgique.

(38) KNETSCH, G.: "Geological Considerations concerning the preservatian of Egyption Monuments, specially of Philae, Abu Simbel and Luxor"; Informe U.N.E.S.C.O., El Cairo, 1959.

(39) Lallement, R. et Deruelle, S.: "Présence de lichens sur les Monuments en pierre: nuisance ou protection?"; Colloque International UNESCO-RII EM, 4 6. París, 1978.

(40) LEwIN, S. Z.: "Recent experience with chemical techniques of stone preservation"; The Treatment of Stone, Bolonia, 1971.

(41) LINKE, W. F.: "Solubilities of Inorganic and metal Organic compounds"; C. van Nostrand Co. Vol. I, págs. 536-556, New York 1958

(42) Lopez Otero, M.: "La técnica moderna en la Conservación de Monumentos", Discurso de ingreso en la Academia de la Historia 3-I-1932. Madrid, 1932.

(43) Luckat, S.: "Stone deterioration at the Cologne Cathedral due to air pollution"; The Conservation of Stone I. Bolonia, 1975.

(44) Mamillan, M.: "La gélivité des matériaux"; Supplement aux Annales de l'Institut Technique du Bâtiment et Travaux Publics, n. ${ }^{\circ}$ 235-236, pág. 1.017, París, 1967.

(45) Mamilan, M.: "Récherches récentes sur le nettoyage des façades en pierre calcaire"; Suppl aux Ann de l'Ins. Tech. Bat. et Trav. Publics, n. 199-200, págs. 858-888, París 1964.

(46) MaSSARI, G.: "Risanamento igienico dei locali umidi"; Edt. Hoepli, 3.a ed. 1967, Milano 1959.

(47) Massari, G.: "Bâtiments humidies et Insalubres: Pratique de leur assainissement"; Travaux et Publications du Centre de Rome, n.॰ X, Edt. Eyrolles, París 1971.

(48) MooRE, W. J.: "Physical Chemistry”, Prentice Hall, págs. 62-63, New York 1950.

(49) Mora, P.: Triennal meeting 3th. Committee for Conservation, ICOM. Madrid, 1972.

(50) Moraru, D.: "Méthodes électriques et électrocinetiques d'assechement"; Conference Moisture, ICOMOS, pág. 99, Roma 1967.

(51) Munnikendan, R. A.: "Further remarks on the impregnation of porous materials with monomers"; Studies in Conservation, vol. 14, n. 3 , (1969), pág. 132, así como "Acrilic monomers sistems for stone impregnation"; en ICC Conference on Conservation of Stone and Wooden Objets, pág. 15, New York, 1970.

(52) NaDAILlaC, L.: "Conservation of Stone and other porous materials"; French Atomic Energy Comission, 3th ICOM-Conservation, Madrid, 1972.

(53) NIESEL, K.: "L'évolution de l'essai de cristallisation"; Colloque International UNESCO-RILEM, pág. 7. París, 1978.

(51) Phillipot, P. et MoRA, P.: "La Conservación de Pinturas Murales"; UNESCO, Museos y Monumentos IX, págs. 181-182, Paris, 1969.

40 
(55) Plenderleith, H. J.: "La Conservación de Antigüedades y Obras de Arte"; ICCR. M. Educación $y$ Ciencia. Madrid, 1967.

(56) Pochon, J.: "Rôle des bacteries dans certaines altération des pierres des Monuments"; Chimie et Industrie, n. ${ }^{\circ} 65,1951$, pág. 496.

(57) Pochon, J. et Jaton, Ch.: "Facteurs biologiques d'altération des pierres: téchniques d'étude"; ICOMOS, Colloques sur l'altération des materiaux pierreux, Bruselas, 1968.

(58) Pochon, J.: "Intervention bacterienne dans la dégradation des Tempes d'Angkor"; Comptes Rendues Acad. Sciences, 248, 1959, pág. 3.644.

(59) Pochon, J. et CoppIer, O.: "Rôle des bactéries sulfato-reductrices dans l'altération biologique des pierres des Monuments"; Comp. Rend. Acad. Sciences, 231, 1950, pág. 1.584.

(60) Pochon, J.: "Facteurs biologiques de l'altération des pierres"; ICOMOS, Colloque sur l'altération des materiaux pierreux, Bruselas 1966, pág. 99.

(61) Rrtchie, T. and Plewes, W. G.: "Moisture penetration of masonery panels"; ASTM-Bulletin TP 183187, 1960, págs. 39-43.

(62) Romanovski, V.: "Etudes sur les pierres calcaires des Monuments"; Corrosion et Anticorrosion, vol. 3, 1955, pág. 191.

(63) Romanovski, V.: "Interet de l'étude du nanoclimat à la proximité des pierres en oeuvre"; Colloque International, La Rochelle, 1972.

(64) Rossi-Manaresi, R.: The Conservation of stone I. Symposium International, Bologna, 1975.

(65) Sanmartin Abelleira, A.: "Tratamiento a la cera contra la descomposición de la piedra"; Simposio Internacional, págs. 201-207, Madrid, 1965.

(66) SCHAFFER, R. J.: "The effects of air pollution on building and stone works"; Thring, M. V. "Air Pollution", Butterworths Sc. Pollution, pág. 71,Londres 1957.

(67) Schatz, A. and MARTin, J. J.: "Destruction of bone and tooth by proteolysis-chelation"; Journal Dentist. vol. 30, págs. 124-134, New York 1960.

(68) Serdet, A.: "Solubilities of Inorganic and Metal-Organic compounds"; D. van Nostrand Co, Princeton 1940, 3. ${ }^{\mathrm{a}}$ ed. vol. I, págs. 264-276.

(69) Serra, M. \& Sarace, G.: "Study of the reactios between gazeous sulphur dioxyde and Calcium Carbonate”; Colloque International, UNESCO-RILEM, 3.7. París, 1978.

(70) Sneyers, R. V.: "Les maladies des pierres de nos Monuments"; Weteuschappelijke Documentetie, Edt. P. F. Merckx, pág. 17, Bruselas, 1961.

(71) Sneyers, R. V. and de Henau, P. J.: "The conservation of stone; UNESCO, Museos y Monumentos XI, pág. 220, París 1968.

(72) Stambolov, T.: "Effect of sulphur pollution on building materials"; IIC London Conference on $\mathrm{Mu}$ seum Climatology, pág. 22, fig. 3, 1967.

(73) Stambolov, T. \& van Asperen De BoeR, R. J. R.: "The deterioration and conservation of porous building materials"; ICOM Comité para la Conservación, Amsterdan, 1969.

(74) Stephen, H. \& Stephen, T.: "Solubilities of Inorganic Compound Pergamon" Press (1963), Vol. I, parte $1 .^{\text {a }}$, págs. 632 y $639-643$.

(75) Tammes, E. \& Vos, B. H.: "Vosh in Bowcostructies", Bouwcentrum Totterdam 1969, citado por Vos, B. H. $(80)$.

(76) TARALon, J.: "Repports d'activités 1971-72 du Laboratoire de Recherche des Monuments Historiques", LRMH; Champs sur Marne, París, 1973. 
(77) TezuKa, Y.: "Development of vegetation in relation to soil formation in the volcanic island of Oshima”; Izu, Japan Journal of Botanic, vol. 17, págs. 371-402, Japan 1961.

(78) VARLAN, E.: "L’etancheité dans la constructión"; Edit. Eyrolles, París 1964.

(79) Vos, B. H.: "Characteristic higric properties of materials and their measurement"; Instituto TNO for Building Materials and Structures, Rijswijk, report B.I. 68/17/3pll. pág. 7, Holanda 1968.

(80) Vos, B. H.: "Hygric properties of materials"; Conferences on the weathering of Stone, págs. 50-68, Bruselas 1968.

(81) Vos, B. H.: "Suction of Graundwater"; Studies in Conservation, vol. 16, n. ${ }^{\circ}$ 1, págs. 129-1454, 1971.

(82) Warnes, A. R.: "Building Stones, their Properties, Decay and Preservation"; Ernest Benn Ltd. Edit. Londres 1926.

(83) Williams, M. E. \& Rudolph, E. D.: "The role of lichens and associated fungi in the chemical weathering of rock"; Mycologia, vol. 66, 1974, págs. 648-660.

(84) WinkleR, E. M.: "Stone: Properties, Durability in Man's Environnement"; Springer-Verlag Wien-New York 1973. Simplificando los cuadros de las páginas 120 y 121.

(85) WiNkLeR, E. M.: "Decay of stone"; ICC Conference on Conservation of stone and wooden objects, vol. I, pág. 13, fig. 3. New York, 1970.

(86) WINKLER, E. M.: "Simple field determination of stone coors"; Colloque International UNESCO-RILEM 3.9., París, 1978.

(87) Winkler, E. M. and Clifton, J. R.: "Solvents for adobe and stone preservation"; Colloque International UNESCO-RILEM, 6.14. París 1978.

(88) Witтe, E. \& Матнот, M.: "The consolidation of tuff of Maastricht by radical polymerization of methacrylates"; Colloque International UNESCO-RILEM, 6.15., París, 1978. 